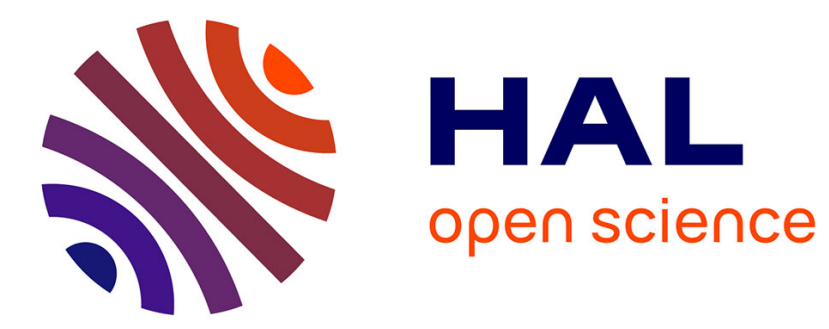

\title{
Les fouilles de la ruelle Saint-Médard à Strasbourg \\ Jean-Jacques Hatt
}

\section{To cite this version:}

Jean-Jacques Hatt. Les fouilles de la ruelle Saint-Médard à Strasbourg. Gallia - Fouilles et monuments archéologiques en France métropolitaine, 1953, 11 (2), pp.225-248. 10.3406/galia.1953.1339 . hal01921345

\section{HAL Id: hal-01921345 \\ https://hal.science/hal-01921345}

Submitted on 3 Mar 2020

HAL is a multi-disciplinary open access archive for the deposit and dissemination of scientific research documents, whether they are published or not. The documents may come from teaching and research institutions in France or abroad, or from public or private research centers.
L'archive ouverte pluridisciplinaire HAL, est destinée au dépôt et à la diffusion de documents scientifiques de niveau recherche, publiés ou non, émanant des établissements d'enseignement et de recherche français ou étrangers, des laboratoires publics ou privés.

\section{(이) $\$$}

Distributed under a Creative Commons Attribution - NonCommercial - NoDerivatives| 4.0 


\title{
LES FOUILLES DE IAA RUELLE SAINT-MÉDARD A STRASBOURG
}

\author{
par M. Jean-Jacques IIATt
}

\begin{abstract}
Nous avons, dans un des précédents numéros de cette revue ${ }^{1}$, exposé les résultats de deux fonilles straligraphiques exécutées en 1947 et 1949 à Strasbourg sous la place de la Cathédrale et la rue du Sanglier. Ces recherches nous avaient permis d'établir sur des bases nouvelles une chronologie de la ville et du camp militaire d'Argentorate, depuis ses origines jusqu'au règne de Valentinien. Mais il nous manquait encore les dernières périodes : la fin du Ive et le début du ve siècle. Nous avions peu d'espoir de pouvoir pousser plus loin, car dans la pluparl des cas, les caves médiévales ont éliminé les dernières couches romaines, et il est même rare de trouver en place la couche d'incendie de 355 .

Contrairement à toute attente, nous sommes lombé, à la ruelle SaintMédard, sur une slraligraphie romaine absolument complète, comprenant toutes les co:ches de la basse époque postérieures à l'incendie de 355, jusqu'au début du ve siècle. Cette fouille constitue done le complément obligé de celles de la place de la Cathédrale et de la rue du Sanglier. Elle nous a permis de combler la lacune qui subsistait encore entre le règne de Valentinien et le Haut Moyen Age (plan, fig. 1).

La ruelle Saint-Médard comporte deux segments se coupant à angle droit, à environ 90 mòtres au S.-0. de l'église Saint-Etienne (chantier de fouilles de 1948) et à une trentaine de mètres au N.-0. de l'enceinte du Bas-Empire, et de celle de Trajan, repérées jadis par Ine Morlet et Forrer ${ }^{2}$ sous le trottoir actuel de la rue des Veaux. Le but principal de ces recherches était de retrouver le fossé et le retranchement du temps de Tibère, dont l'emplacement avait été f:xé par une conjecture de Forrer ${ }^{3}$ de telle façon, qu'il devait couper la par-
\end{abstract}

(1) Gallia, VII, 1949, 2.

(2) FORnir, Strasbourg-Argentorate, I, pp. $23 \pi$ à 241.

(3) Ibid., pp. 261 et pl. XXIII. 
tie de la ruelle Saint-Médard qui est orientíe N.E.-S.O., à peu près en son milieu. Cefte supposition s'est rívélée exacte, ì quelques mètres près.

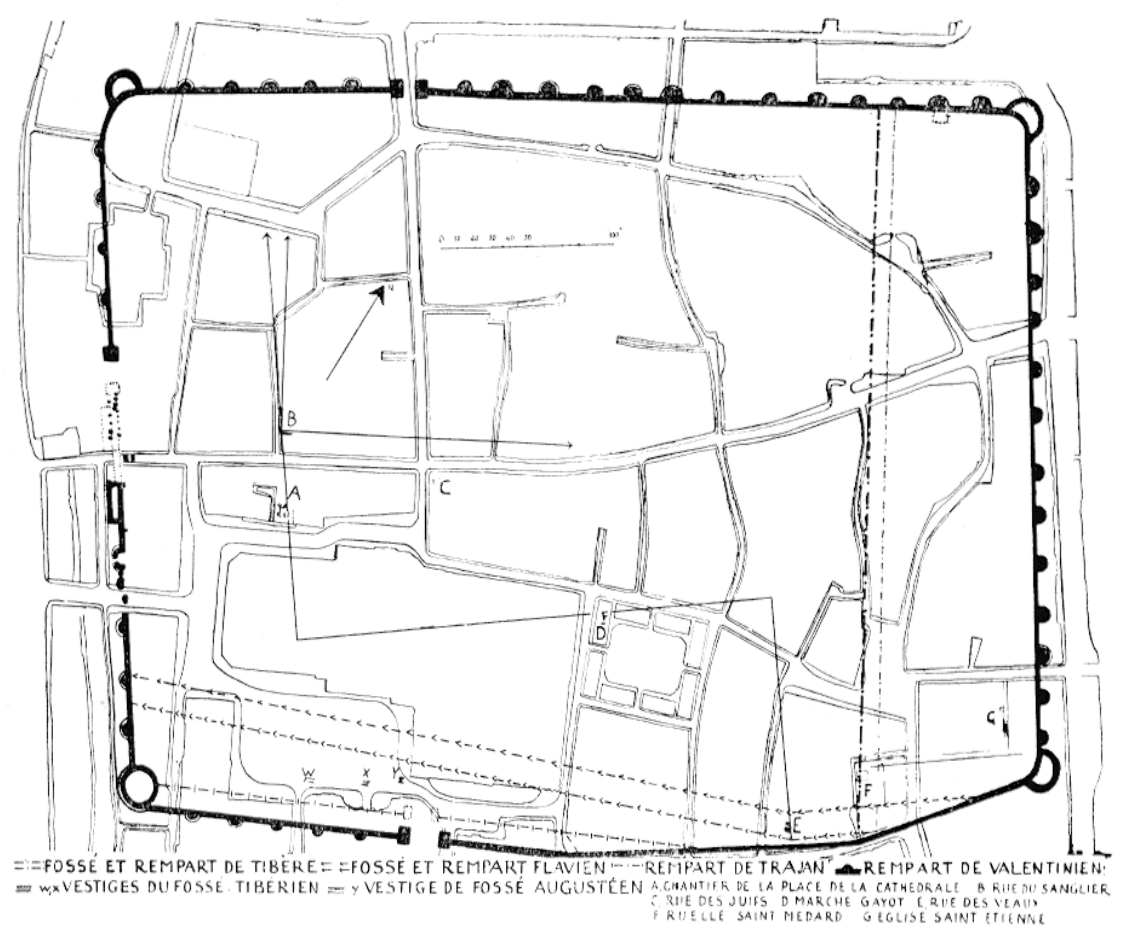

FIG. 1. - Le camp romain d'Argentorate. Mise en place des différents vestiges découverts entre 1947 et 1952. En A-B, Ia stratigraphie de la rue du Sanglier et de la place de la Cathédrale. En F, la stratigraphie de la ruelle Saint-Médard.

L'emplacement fouillé a été occupé, au cours des quatre siècles gallo-romains, par des installations et des bâtiments de caractère très divers. Nous avons mis au jour, en restituant l'ordre chronologique : $1^{\circ}$ le fossí de Tibire, at des indices du retranchement en bois et en terre qui lui correspond; 20 un croisement de rues intérieures du camp, datant de la période flavienne; ... $3^{n}$ des vestiges de murs ornés de fresques, appartenant à deux séries de bâtiments militaires du début du $\mathrm{II}^{\mathrm{e}}$ siècle; - $4^{\circ}$ des vestiges d'habilations d'artisans indigènes de la fin du $\mathrm{II}^{\mathrm{e}}$ siècle, et les cailloutis superposés de trois voies de la même époque; $-5^{\circ}$ des caves de baraquements militaires du début du III ${ }^{\mathrm{e}}$ siècle, remplies des débris calcinés provenant de l'incendie de 235; -- $6^{\circ}$ les témoins de trois sols de place, en terrazzo, de la fin du III siècle; $7^{\circ}$ les vestiges d'un grenier à grains du IV siècle, incendié à trois reprises. ainsi que des substructions de petits bâtiments militaires proches de l'enceinte; -... $8^{\circ}$ une voie dallée, et les fondations, en matériaux de remploi, de baraquements en bois de la première moitié du ve siècle. 


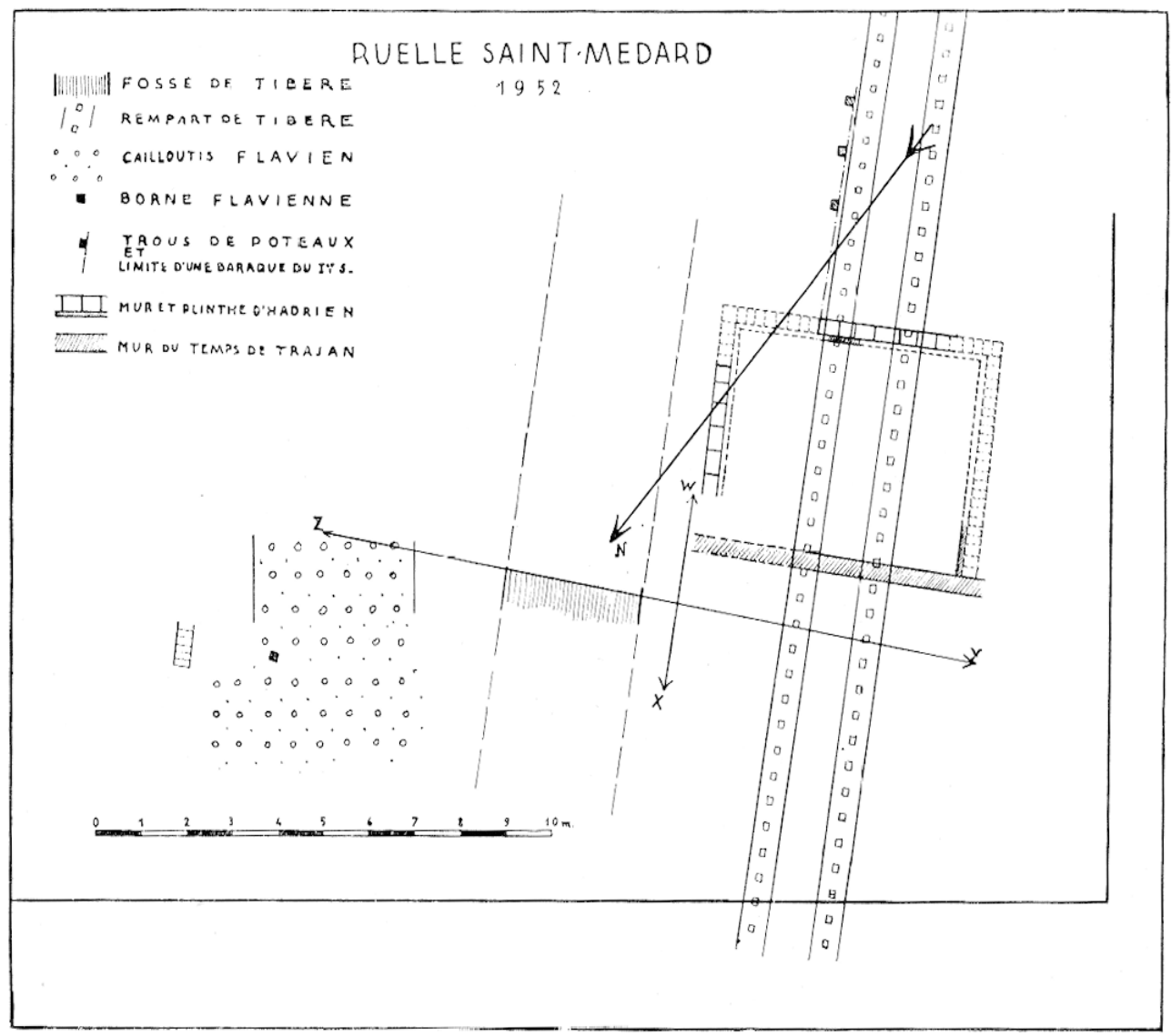

FIG. 2. - Ruelle Saint-Módard. Plan schématique des vestiges du IIaut-Empire. Fouilles 1951-1952.

\section{1" Le fossé et le retranchement en bois de l'époque de Tibère.}

La fortification du temps de Tibère comportait un rempart de terre, et un fossé, à l'extérieur duquel courait une file de chevaux de frise ou une palissade (fig. 2).

Large de $6^{\mathrm{m}}, 60$ (20 pieds romains) et profond de $2^{\mathrm{m}}, 70$ (9 pieds), le fossé avait été creusé dans l'argile, le sable et le gravier. Il était encore parfaitement visible, et se détachait, en coupe, sur les terrains non remanićs. Le fond, notamment, rempli d'une boue sableuse et limoneuse noirâtre, se distinguait avec une particulière netteté du sable rouge de la Bruche et du gravier rhénan.

Il avait une forme assez complexe : fond plat, parois fortement incurvées ot convexes. Cette forme suppose un fossé sec, armé de pieux de défense pourvus de crochets. C'est le type même de la fossa lateribus curvis ${ }^{4}$, de la période césarienne, adapté à l'échelle d'un retranchement permanent.

(4) Mathlinat, La lechnique des retranchemenls de César d'après les fouilles de Nointel, Gallia, I, 1943, 1, p. 94. 
Les traces du rempart nous sont apparues sous la forme de deux fosses étroites, orientées. S.-E.-N.O., remplies d'une terre noire et grasse qui tranchait sur le fond plus clair de l'argile, ct profondes de $1 \mathrm{~m}, 20$. Ces deux tranchées avaient été sans doute creusées pour loger les bases des poutres de l'armature en bois du rempart. Ce dernier ćtait vraisemblablement pourvu d'une charpente intérieure et d'un blindage extérieur en bois, comme celui de Vetera ${ }^{5}$. La figure $3 b$ en donne une restitution.

L'emplacement du retranchement avait été recouvert par la couche d'incendie de 70, mais le rempart en bois et en terre avait déjà été nivelé à cette date, et le fossé comblé. Ge qui le prouve. c'est d'abord la structure des couches de terrain et l'absence romplète dans la couche de destruction de vestiges ralcinés du rempart. C"est ensuite que nous avons trouvé, au-dessus même du fossé un sol calciné el des trous de poleaux. Ces vestiges appartiennent à une habitation indigène en bois, édifice à la fin du rìgne de Claude à l'emplacement du rempart désafiecté, puis incendie en 70 ap. J.-(:. Ja couche d'incendie contenait une assez gramde guntité de ecramique, notamment de la signillée de la Graufesenque du temps de Claude à Néron (voir fig. 5).
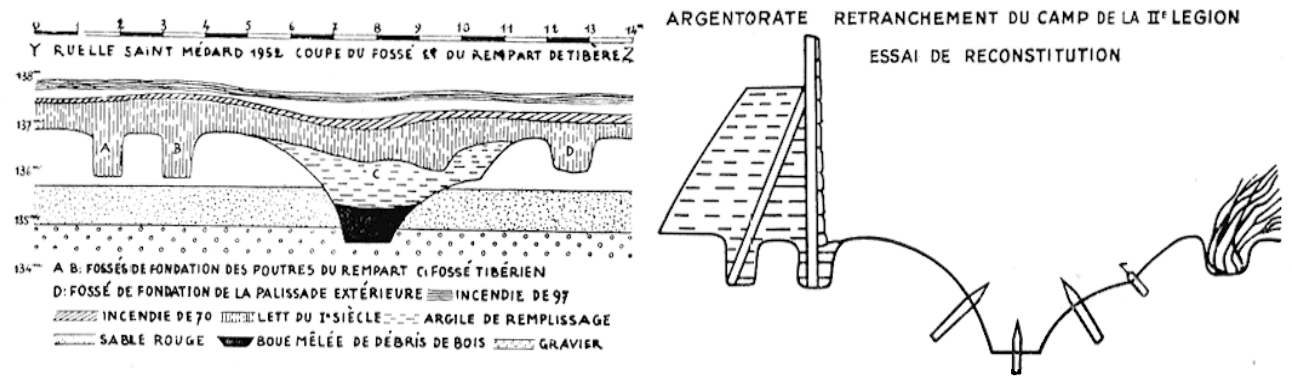

Fic. 3 a el b. - Coupe $(a)$ et reconstitution (b) du retranchement de la 11 "'śgion.

$2^{\circ}$ Carrefour de la via sagularis flavienne et d'une voie d'accìs au rempart.

Dans la partic orientale du chantier (plan, fig. 2) nous avons dígngé un cronisement de deux voies intérieures du camp flavien.

Voici comment se présentait, en eet endroit, la succession des niveaux, en partant du terrain naturel (limon marron clair, à veines rougeâtres) :

137m,45 : argile naturelle, base du cailloutis of fond de la rigole d'une route du tempss de Tibère;

137 ${ }^{\mathrm{m}}, 65$ : sommet du cailloutis de la premiere route;

137m,70: sommel d'une couche d'argile de remblai;

137m,75: sommet de la couche d'incendic de 70;

137m,90: sommet d'une couche de remblai flavienne;

$138^{\mathrm{m}}, 20$ : sommet du cailloutis de la route flavienne.

Dans la couche de remblai flavien, à peu près à l'emplacement du croisement des voies, avait été placće, de façon visiblement intentionnelle, une petite pierre cubique

(5) Grenter, Manuel d'archéologic gallo-romaine, I, p. 361. 
en grès vosgien (tig. 6). Nous pensons qu'il s'agit d’une borne provisoire, ayant servi aux géomètres militaires, aux gromatici, pour placer leur instrument, lors de la castramétation flavienne. Cette borne-repère avait été enfoncéc dans l'argile de remblai, avant l'établissement de la route, pour le tracó de laquelle elle avait été utilisée. Sa base de trouvait à $137 \mathrm{~m}, 70$.

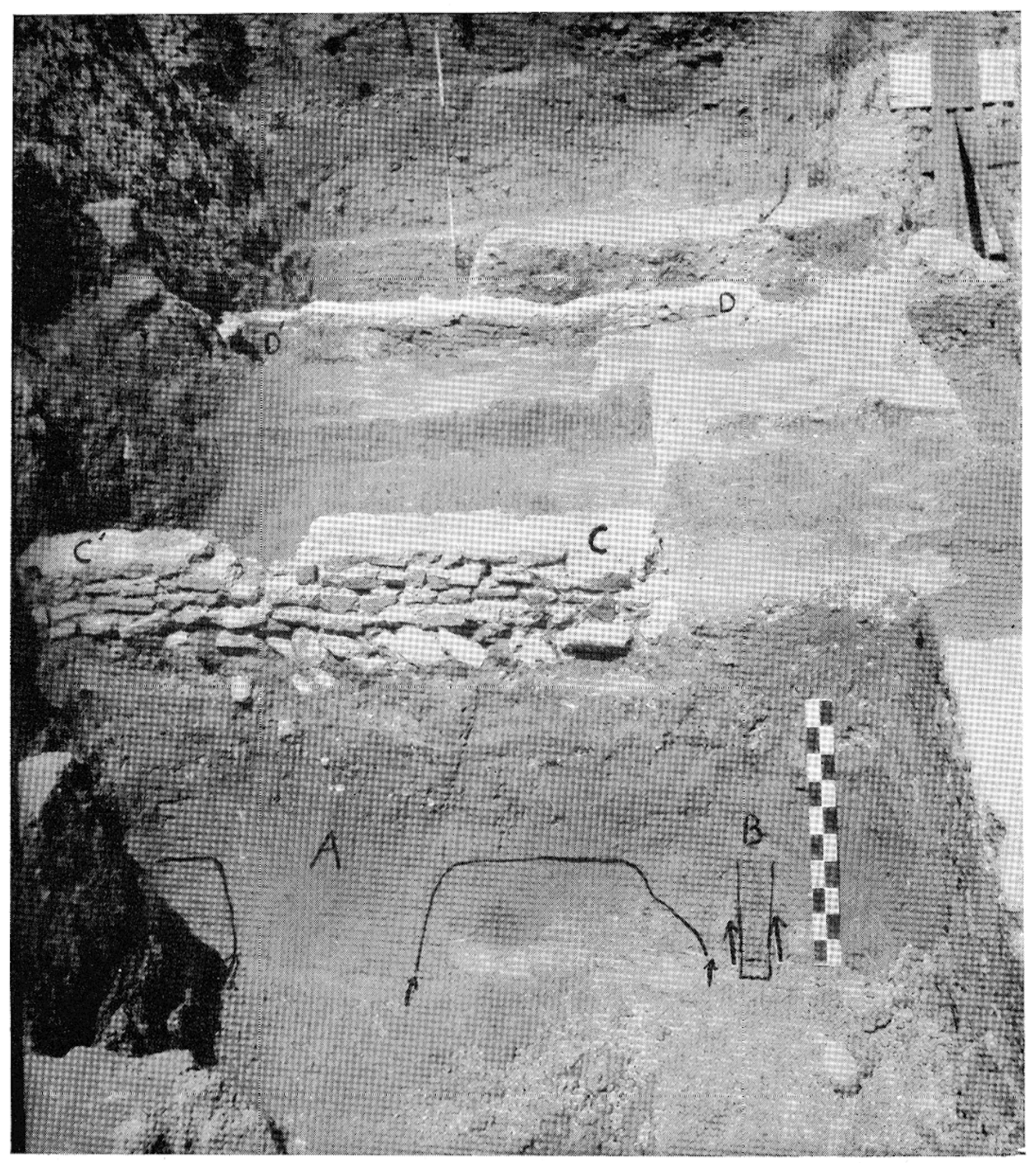

Fig. 4. - Vue générale du chantier d'Est en Ouest. A, B: fosses de fondation du rempart de Tibère. $\mathrm{CC}^{\prime}$ : mur du temps d'Hadrien. $\mathrm{DD}^{\prime}:$ mur du temps de Trajan.

I] y aurail donc eu là l'intersection de deux lignes d'arpentage, et la limite entre deux strigae. In distance entre la borne et la via sagularis découverte en 1948 sous 

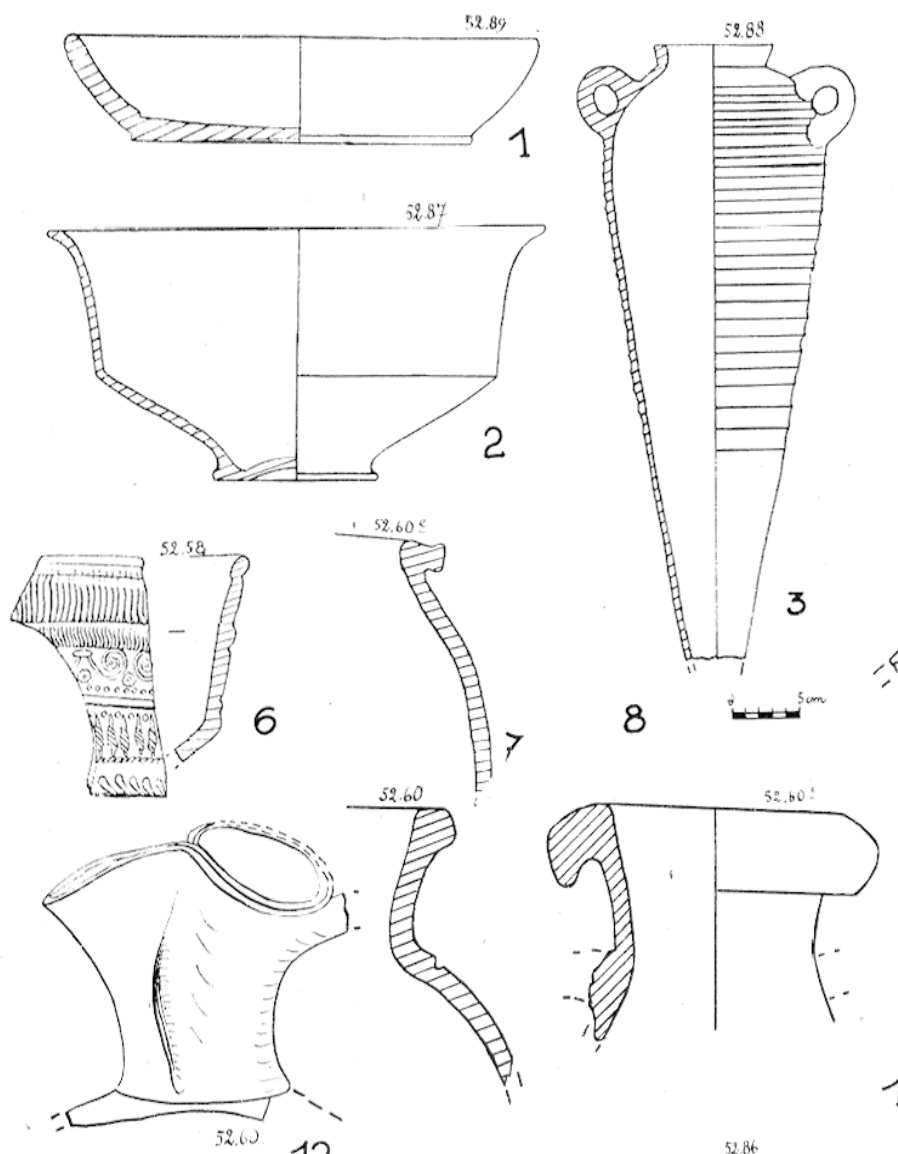

12

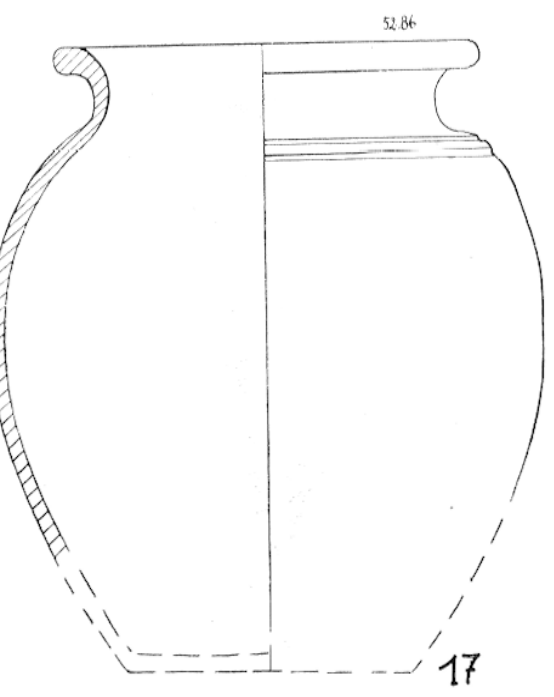

13
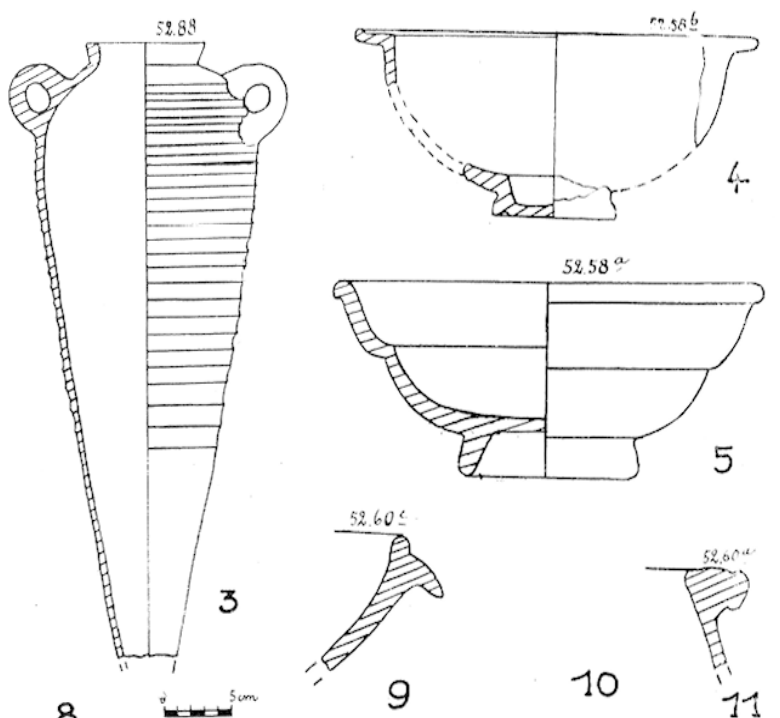

10 11
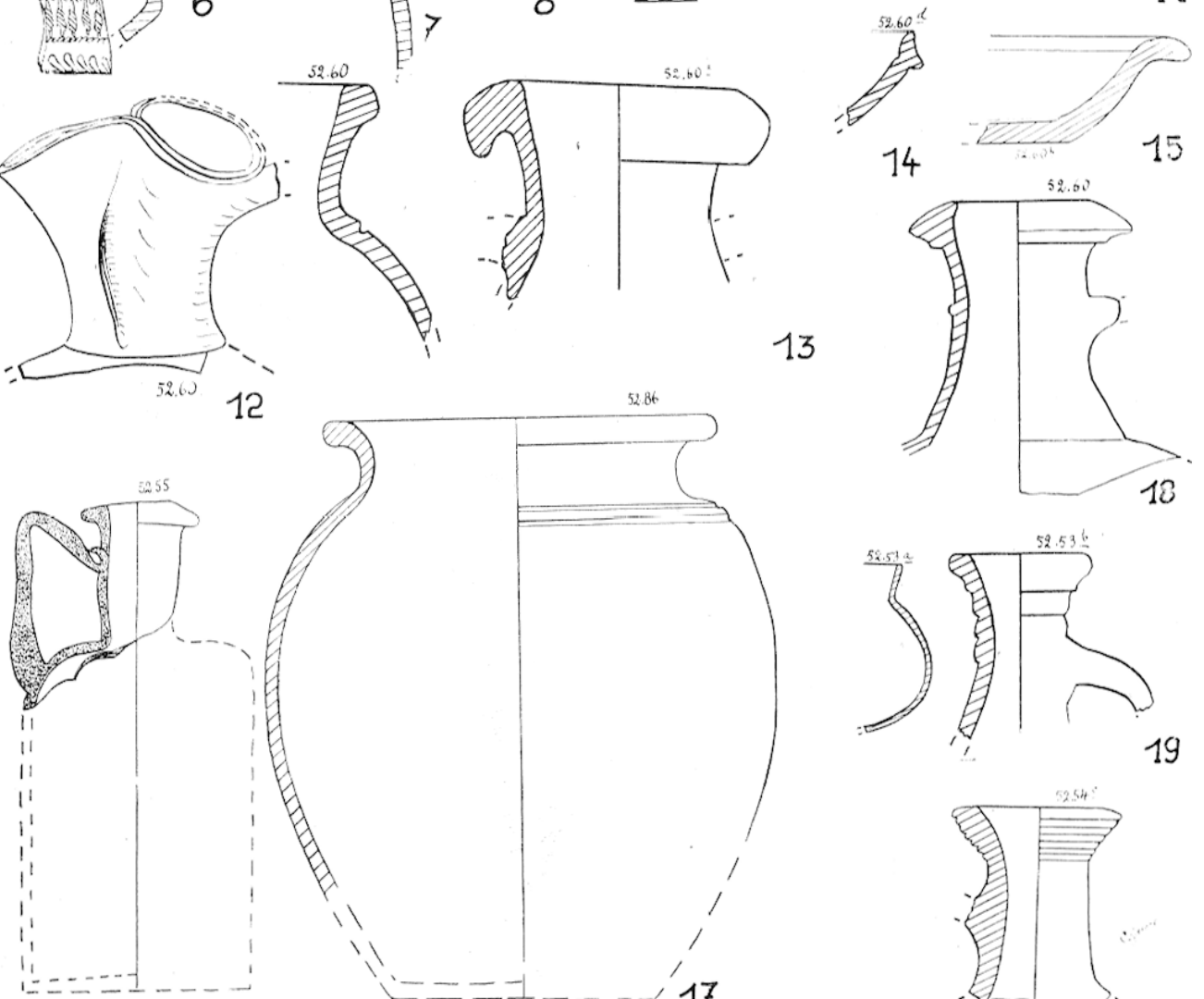

\section{ID:}

Fı. J. - Círamique découverte dans les couches d'habitats du rigne de Claude, dans les couches d'incendie de 70 , et dans les couches de remb'ai flaviennes: 1 . assiette en terre jaune pảle; 2. coupe carénće en imilation de terre sigillée helvétique; 3 . petite amphore; 4. coupe à marli, en terre sigillée helvélique; 5. coupe Drag. 27, en terre sigillée de La Graufesenque; 6. vase Drag. 29, de La Graufesenque; 7, 8. vases ovoïdes en terre orangce pâle; $9,10,14$, 15 , terra nigra; 11. rebord de marmite en terre brune; 12, 13, 18, 19, 20. cruches en terro orangée; 17. vase ovoüde en terre orangée; 16. flacon cn verre vert (en bas, à gauche). 


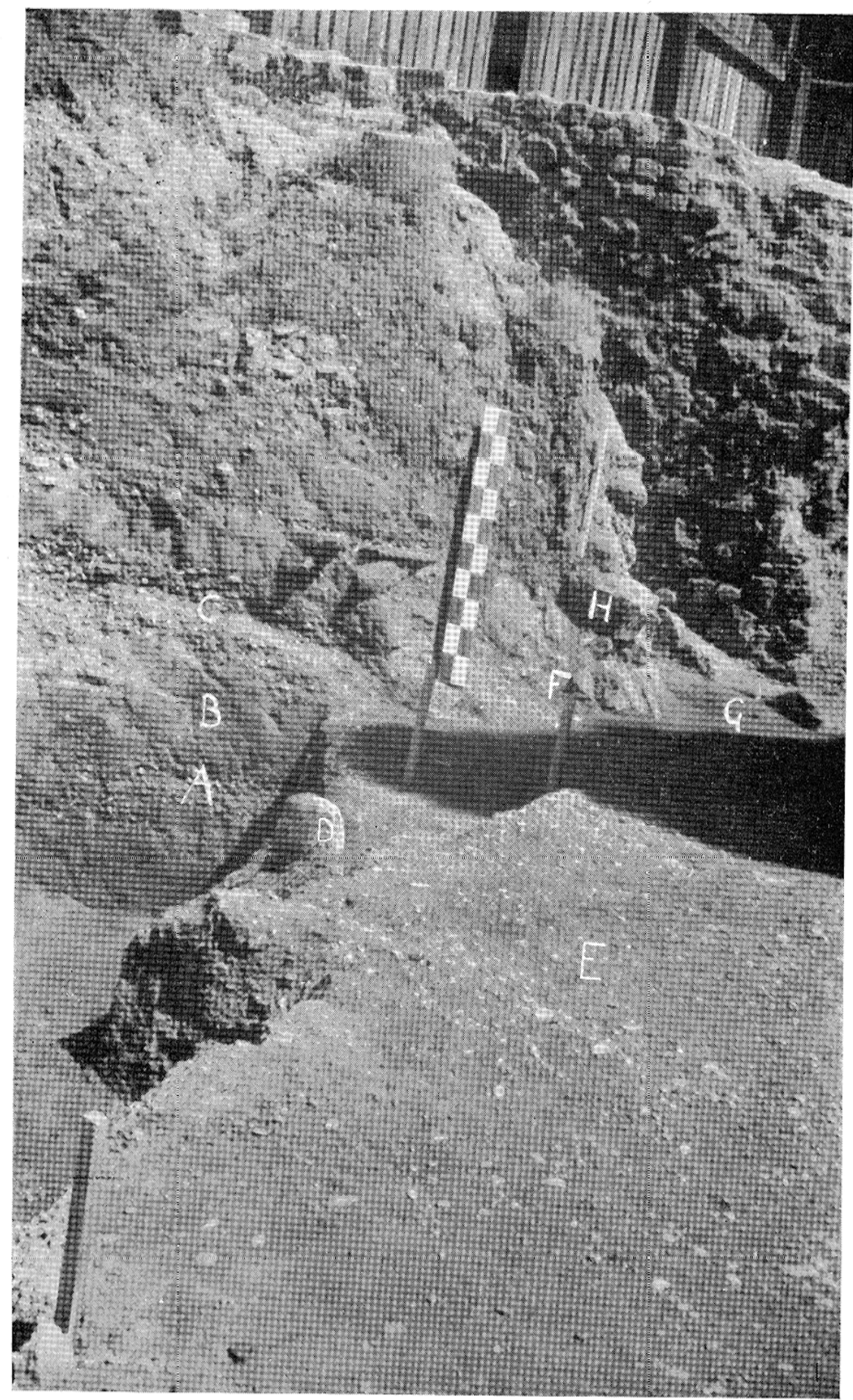

FIG. 6. - A, premier caillontis (Tibère); B, couche de remblai du temps de Claude; C, via sagularis flavienne; D, borne de castrametation flavienne; $\mathrm{E}$, surface de la voie flavienne; $\mathrm{F}$, hérisson en tuiles; $\mathrm{G}$, incendie de 97; $\mathrm{H}$, segment de mur du temps d'Hadrien. 
l'église Saint-Etienne doit correspondre à la largeur d'une striga du camp l'Argentorate. Elle est de $72^{\mathrm{m}}$ ( 216 pieds) alors qu'd Neuss elle est de $80^{\mathrm{m}}$ ( 240 pieds), distance canonique, d'après Hygin ${ }^{6}$. Il est vrai que le camp de Strasbourg n'a que 520 mètres de long, alors que Neuss en a 720. De la même manière, l'intervallum, ou espace vide entre le rempart et la via sagularis, qui est à Neuss de 33 mètres ou 100 pieds, n'est à Strasbourg que de 21 mètres, ou 70 pieds. L'espace restreint dans lequel ils étaient obligés de placer leur camp, pour bénéficier de la protection naturelle de deux anciens cours d'eau, utilisés comme fossés, a contraint les gromatici à resserrer notablement les dimensions normales de la striga. Cette constatation est importante pour la reconstitution du quadrillage intérieur du camp.

La via sagularis flavienne se trouve à environ 30 mòtres du tracé de l'enceinte de Trajan, c'est-àdire $9^{\mathrm{m}}$ plus à l'Ouest qu'il ne scrait normal, étant donné la dimension réduite de l'intervallum. Cette constatation nous a amené à chercher, à l'inlérieur de l'enceinte de Trajan, les vestiges de l'enceinte flavienne. Nous cu avons effectivement découvert le fossé rue des Veaux.

La surface des deux voies de la ruelle Saint-Médard était couverte de gravier du Rhin fortement damé, les plus gros graviers se trouvant à la base. La via sagularis découverte sous l'église Sainl-Etienne ćtait eonstituée exactement do la même faģon.

La via sagularis flavienne semble avoir été prócédée, dis l'époque de Tibère, d'une voie de communication extérieure au rempart. I'n cailloutis plus ancien, épais de $0^{\mathrm{m}}, 20$, apparaissait en coupe sous la première (fig. 6). Il a été impossible d'en préciser la largeur et l'orientation exacte. Co cailloutis tibérien élait nettement délimité par une rigole, creusće dans l'argile naturelle. Route et rigole avaient ensuite été remblayées avec l'argile marron, grasse, a veines rougeâtres, qui conslituait la plus grande partie du remplissage du fossé tibérien.

\section{$3^{\circ}$ Les battiments militaires du début du Ile siècle.}

a) Edifice du temps de Trajan. - Les vesliges de construclions militaires consistent en cinq segments de murs, appartenant ì deux ćpoques différentes (voir plan, fig. 2).

Jee long de la tranchée de sondage du fosscí, a été dígagé un mur en morceaux de luiles à rebords; épais de $0^{\mathrm{m}}, 30$ à $0^{\mathrm{m}}, 35$, couvert encore partiellement d'un enduit it la fresque (fig. 7). Ce mur reposait sur un hérisson en pierres sèches, établi lui-même immédiatement au-dessus de la couche d'incendie de 70 . Comme le sol, en terre battuc, correspondant à l'arrêt de l'enduit peint, et à 111 r'essaut en béton encore attaché au mur, se trouvail séparé de la couche d'incendie de 97 pate une couche de remblai de (om,10 d'éprasseur, il est possible de dater le mur de la périnde de Trajan.

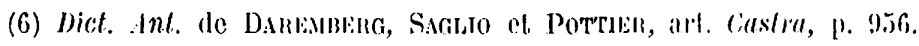


Il avait été conslruit avec des fragments de tuiles à rebords posés à plat, les rehords des tuiles, laissćs à l'extérieur; constituant le parement. Ces fragments de tuiles claient joints par un mortier à la chaux très compact et résistant, contenant une faible proportion de sable et de gravier gris. Beaucoup de ces débris de tuiles portaient des marques do la VIII légion huguste, analogues à celles que nous avons trouvées dans les sols de baraquements militaires construits sous Trajan, lors des fouilles de l'église Saint-Htienne?

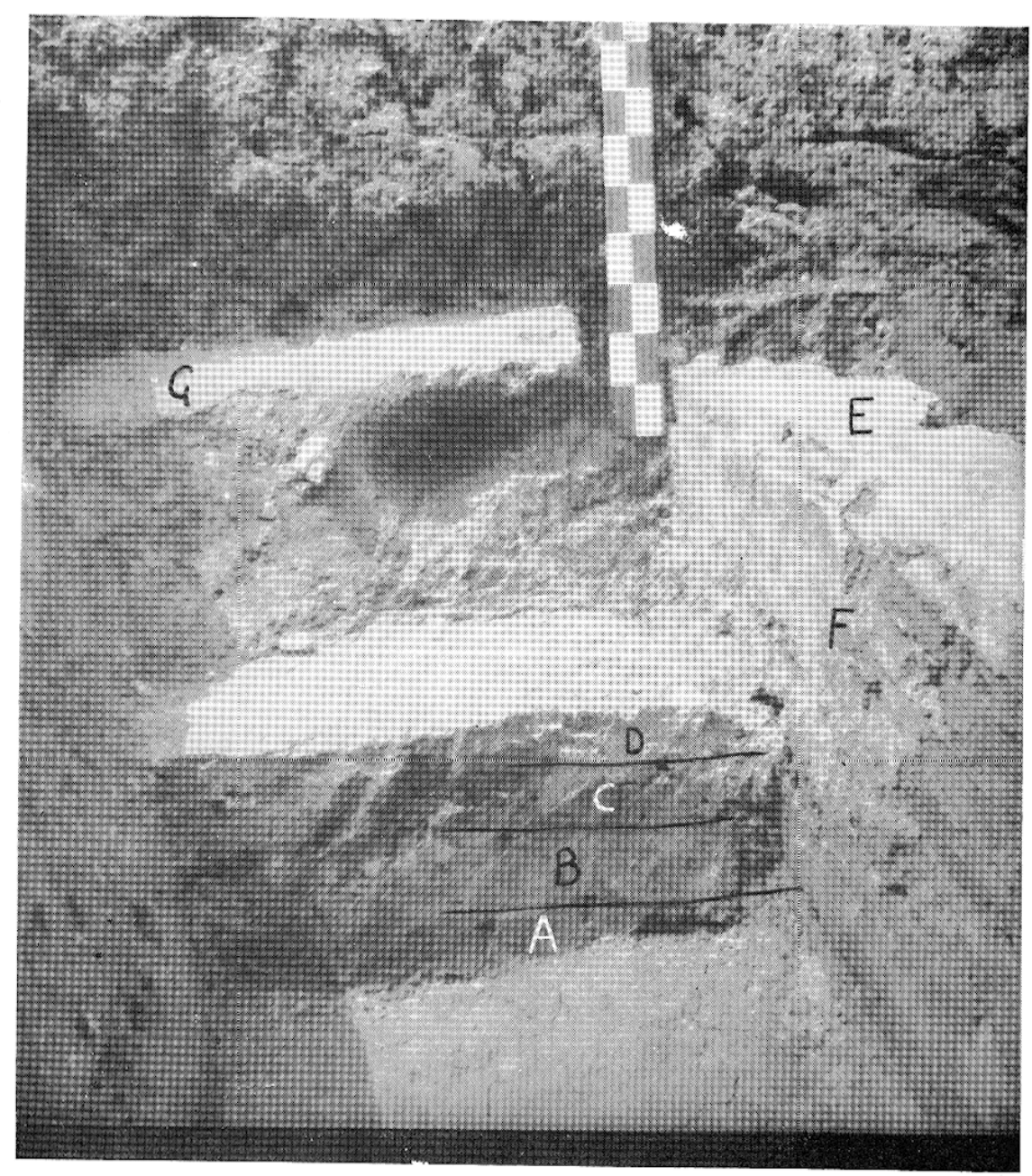

Fici. $7 .-$ Superposition du mur de Trajan et du mur d'Hadrien : A, incendie de 70; B, remblai flavien; $C$, incendie de $97 ; \mathrm{D}$, remblai de Trajan; $\mathrm{F}$, mur de Trajan; $\mathrm{F}$, frcsque adhérant cncore au mur; $G$, p'inthe du mur du lemps d'Hadrien.

Voici comment se présentail la coupe stratigraphique à l'aplomb de ce mur :

de $137^{\mathrm{m}}, 53$ à $137^{\mathrm{m}}, 65$ : couche d'incendie de 70 ;

" $137 \mathrm{~m}, 65$ à $137^{\prime 1}, 75$ : remblai flavien;

(7) Catiers d'Archeologie st d'Histoire d'Alsace, 1949, p. 267, pl. V. 
de 137m,65: base du hérisson en pierres séches du mur de Trajan;

" $137^{\mathrm{m}}, 75$ à $137^{\mathrm{m}}, 80:$ couche d'incendie de 97 ;

" $137 \mathrm{~m}, 80$ à $137 \mathrm{~m}, 92$ : remblai du temps de Trajan;

" $137_{\mathrm{m}}^{\mathrm{m}}, 92$ à $137^{\mathrm{m}}, 98$ : sol en terre battue du temps de Trajan; 137m,95 : base de la partie appareillée du mur de Trajan; $138^{\mathrm{m}}, 30$ : sommet de la partie conservée du mur de Trajan.

(Ce mur, seul reste subsistant en cet endroit d'une construction assez importante, dont les vestiges doivent se prolonger sous les maisons actuelles de la ruelle Saint-Médard, paraîl avoir été intentionnellement détruit et remblayé une trentaine d'années après sa r'onstruction.

l.e sol du temps de Trajan cilail en effel surmontí, colre $137^{\mathrm{m}}, 98$ et 138 $138^{\mathrm{m}}, 38$, d'une couche de destruclion el de remblai contenant de nombreux débris de tuiles à rebords et d'enduil à la fresque, ainsi que de la céramique du début du II $^{\mathrm{e}}$ siècle. Les morceaux de fresques, d'une belle technique, portaient encorce des éléments de décoration assez bien conservés : frises de feuilles stylisées, palmetles, trones et branches d'arbres, draperies flottantes. Il s'agit sans doute d'un décor de forêt, formant fond, sur lequel évoluaient des danseuses. Des fresques du même genre. el sans doute de la même époque ont été trouvées à proximité des thermes mililaires du quarlier Saint-T'homas ${ }^{8}$. Elles ont pu être parliellement reconstituées et sont actucllement exposées dans une salle du Musée archéologique.

Celles de la ruelle Saint-Médard sont malheureusement en trop mauvais ćlat pour que nous ayons pu en faire de même pour elles. La peinture, on rehauts de conleur's vives, sur fond bleu ou vert, était fragile et s'est Irouvée fréquemment délavée. La dícouverte esl cependant significative, car clle nous permet de dater asse\% exactement un ensemble de peintures à la fresque que leur slyle et leur lechnique permet de considerer comme sensiblement contemporaines, celles de la place Saint-Thomas. Cies dernières se distinguent d'ailleurs nellement de celles de la place Klóber (Maison Rouge) ". beaucoup plus brillantes de style et beaucoup plus parfailes de technique, sensiblement plus solides aussi, ch que les déouvertes de crimmigue permellent de daler de la période flavienue.

b) Edifices du temps d'Hadrien. - $A$ co premier ćdifice devait cn sucéder un aulre, sous Hadrien, vers 120 ap. J.-(., dont qualre segments de murs nous ont été conservés (plan, fig. 2). Ln effect, le mur en tuiles à rebords itait surmonté d'un autre étage de substructions, construites en moellons calcaires, et pourvues d'une plinthe en quart de cylindre (fig. 7 et 16). La base de la plinthe,

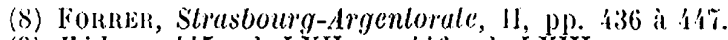

(9) lbid., p. 445, pl. LXII; p. 446, pl. IXIII. 
marquant le niveau du sol de ces nouveaux bàtiments, était à $138^{\text {m }}, 32$, et son sommet, correspondant à la partie inférieure d'un enduit à la fresque, à $1: 38^{\mathrm{m}}, 44^{4}$. La partie appareillée du mur, en blocage de pierres calcaires liées par un morlier à la chaux contenant une forte proportiou de gravier et de sable gris, reposail, à $138^{\mathrm{m}}, 11$, sur un hérisson de pierres calcaires posćes obliquement et it sec, à l'altitude de $137^{\mathrm{m}}, 90$. L'épaisseur de ces murs était également d'un pied romain, environ.

La plinthe, couverte extérieurement de poussière de luileaux mêlée de chaux, était constituée intérieurement par un agrégat de mortier, de fragments de briques et de petites pierres calcaires. Le sol correspondant ì la base de la plinthe était en argile durcie et damée, portant encore par places des empreintes de plinches en bois. Il avait donc été recouvert d'un plancher.

Il était surmonté d'une couche de démolition el de remblai contcnant de nombreux débris de céramique, notamment de la sigillée à reliefs de Rheinzabern du tempz des Antonins. A ce niveau, nous avons également trouvé des fragments d'enduit à la fresque, décorés de façon heaucoup plus élémentaire que ceux de la période précédente : ils portaient simplement des traits rectilignes et courbes de couleur noire, verto ou rouge.

Stratigraphie à l'aplomb du mur d'Hadrien dans la partie occidentale du chantier : 137m, 40 : sommet du remplissage du fossé tibérien;

137m,54: couche d'habitats du temps de Claude à Néron;

137m, 70 : couche d'incendie de 70;

$137 \mathrm{~m}, 78$ : remblai flavien;

$137^{\mathrm{m}}, 82$ : incendie de 97 ;

137m,90: base du hérisson de fondation du mur d'Hadrien;

138m,11 : sommet du hérisson de fondation du mur d'Hadrien;

138m,32: base de la plinthe, sol en terre battue du mur d'IIadrien;

138m, 14: sommet de la plinthe.

$4^{\circ}$ Vestiges de demeures artisanales de la fin du $I I^{\circ}$ siècle.

Les bătiments du temps d'Hadrien semblent avoir élé détruils et inlentionnellement rasés vers 160 ap. J.-C. Ils furent remplacés par des habitats en bois et en torchis, dont les fonds de caves, traversant à maintes reprises les couches sous-jacentes, contenaient une très grande quantité de cćramique, notamment de la sigillée à reliefs de lheinzabern, des objets divers en bronze et en fer (voir fig. 9), ainsi qu'une monnaie de Marc Aurèle.

La présence dans ces fonds de caves, ayant servi fréquemment de dépotoirs, de nombreux débris de bronze ouvré, d'objets inachevés ou en cours de réparation, et de scories de fonte, nous permet de supposer que l'emplacement avait été concédé, après le départ de la garnison pour le limes, à des artisans indigènes travaillant en partie pour le compte de l'armée. Aux fibules et aux 
bijoux de bronze, s'associaient en effet quelques armes ou objets d'équipement spécifiquement militaires : écailles de lorica squamata (fig. 3, 39), fragment de cotte de maille en f'er (fig. 9, 20), pointe de lance inachevée, abandonnée en cours de forgeage (fig. 9,21 ), ainsi que des boucles de ceintures el des appliques en bronze du type de celles qui ont ché trouvées en grandr abondanee dans les camps du limes (fig. 9, 25, 23, ctc...).
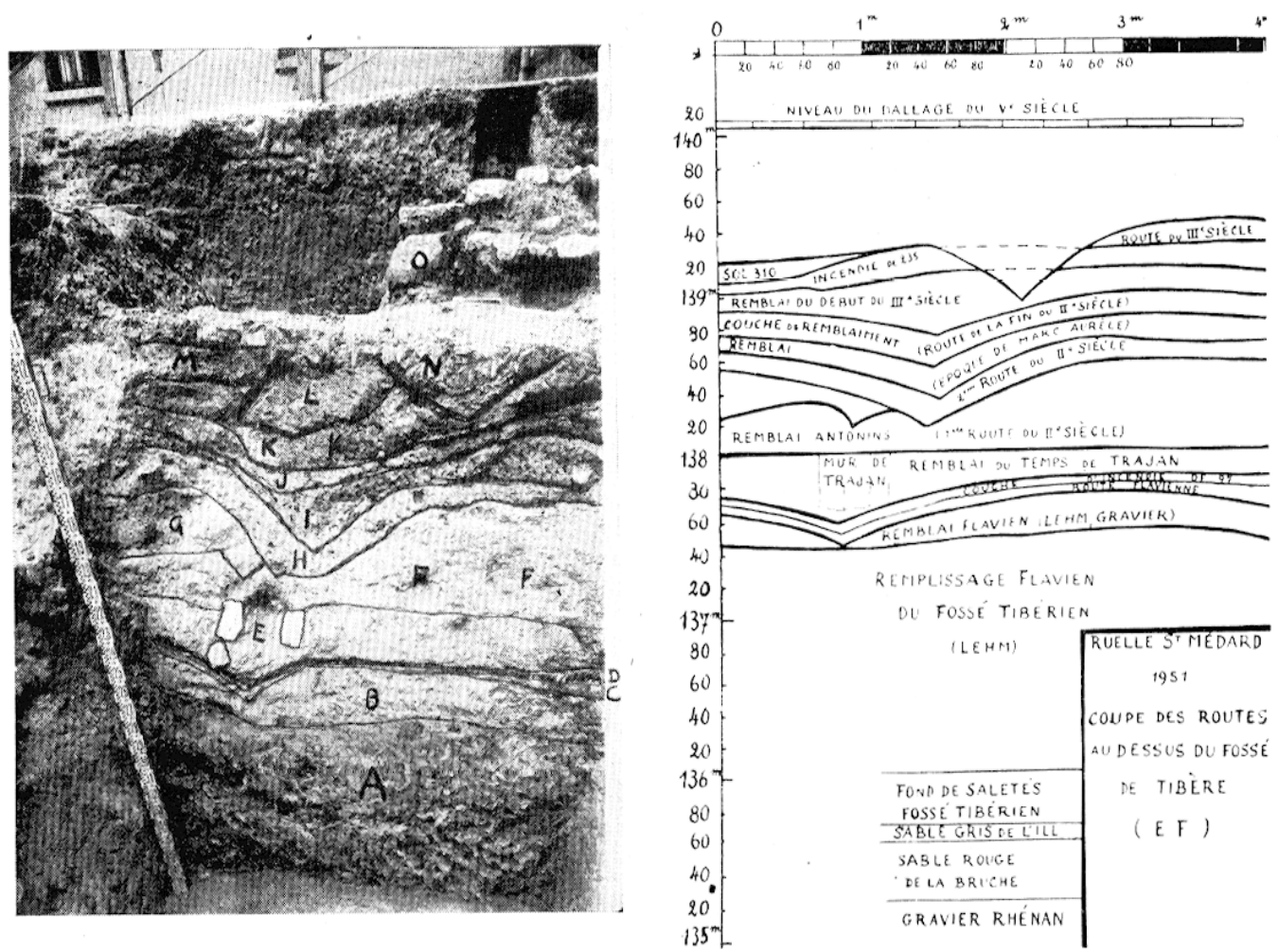

Fia. 8. - Coupe des murs CT des couches de terrain du Ire et du III siècle. $A$ droile: Coupe en $\Lambda$ R du plan de la figure 11 au-dessus du fossé de Tibère. 0, mur en pierres et torchis de Valenlinien; $N$, rigole de la route du III siècle; $M$, remblai du $\mathrm{IV}^{\mathrm{e}}$ siècle; $\mathrm{L}$, poche, restant de la couche d'incendie de 235; K, remblai du début du nir siècle; J, route de la fin du $\mathrm{II}^{\mathrm{e}}$ siècle; I, remblai d'incendie (époque de Marc $\Lambda$ urèle); $\mathrm{H}$, deuxième route du $\mathrm{II}^{\mathrm{e}}$ siècle; $\mathrm{G}$, première route du $\mathrm{II}^{\mathrm{e}}$ sic̀cle (sur creusée) : remblai du temps d'Antonin; F, remblai du temps d'Antonin; E, mur de Trajan (hérisson); D, couche d'incendie de 97 ; $\mathrm{G}$, route flavienne; $\mathrm{B}$, remblai flavien; $\Lambda$, remplissage flavien du fossé tibérien.

Entre le règne d'Antonin et la période des Sévères, plusieurs générations successives de ces habitats semblent s'être succédé. A défaut de sols nettement séparés, nous avons pu distinguer les niveaux de trois rues superposíes. L'une d'entre elles, la deuxième (fig. 8) a été remblayce avec des débris divers, provenant d'édifices incendiés.

Comme nous n'avons pas trouvé sur place dans les couches d'habitats de traces d'incendie de celle époque, nous supposons que ces malíriaux de rem- 

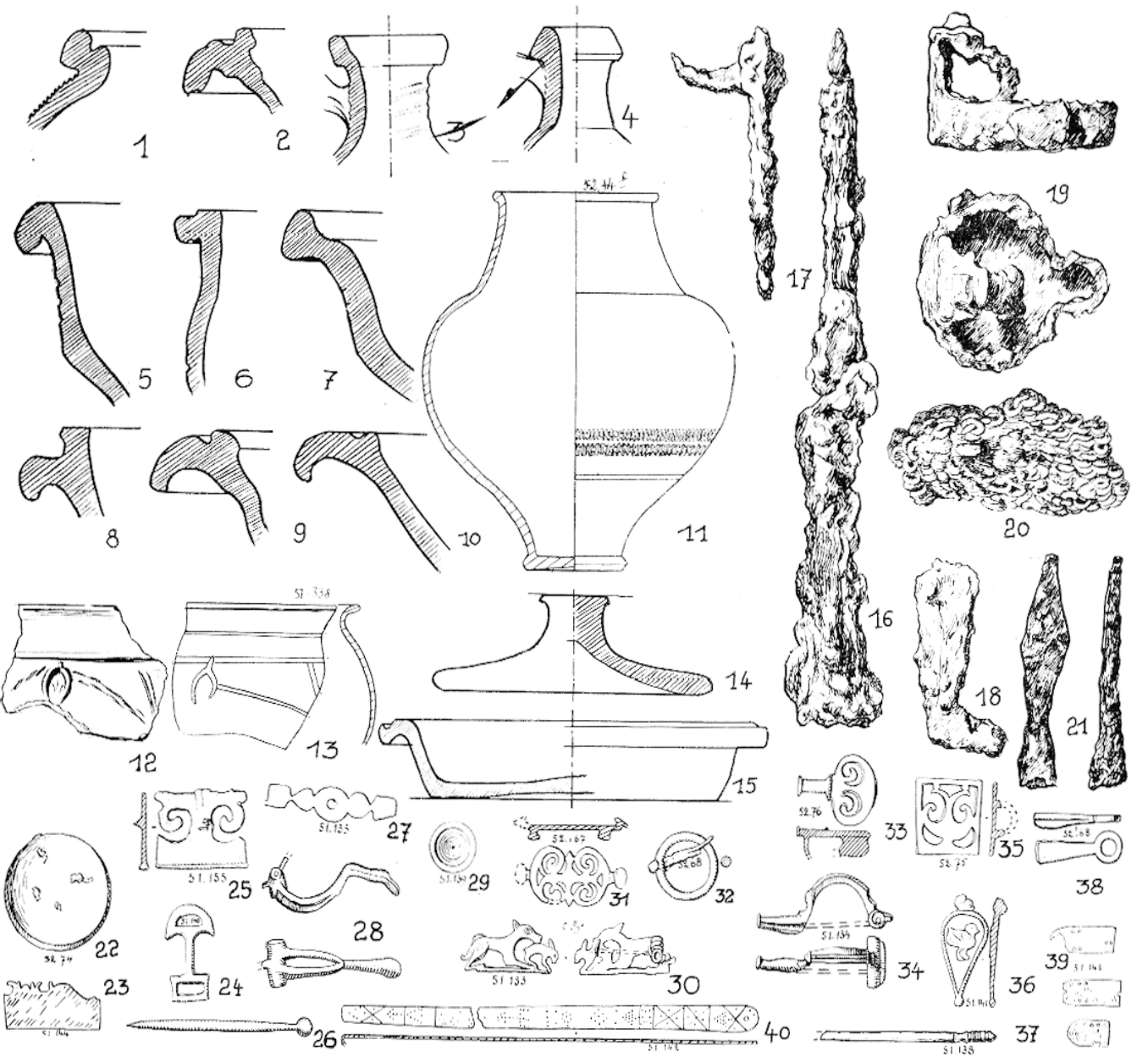

20

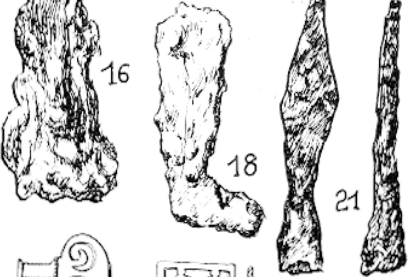

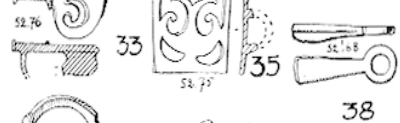<smiles>C=CCCOCC</smiles>

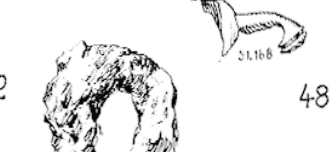
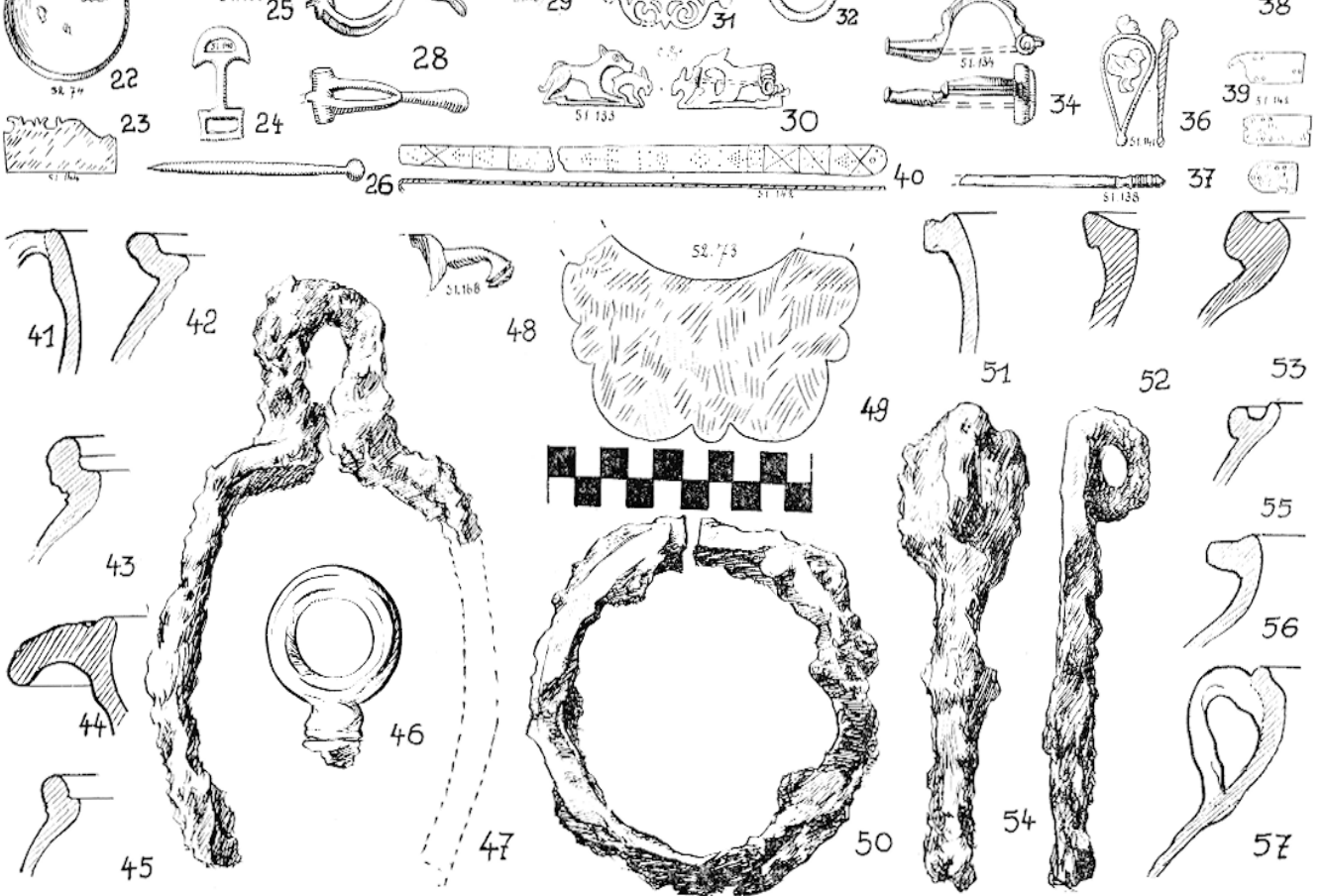

Fig. 9. - Céramique et objels divers: I. Couches d'habitals de la fin du II siècle: 1, vase ovoïde en terre grise; 2, 8, 9, 10, rebords de mortiers; 5, rebord de marmite; 7, rebord de braséro; 3 et 4, cols de cruches; 11, gobelet en terre sigillée régionale; 12, 13, gobelets rhétiques; 14, couvercle; 15, assiette en céramique peinte; 17, penture de porte; 16, pilum en fer; 19, lampe en fer; 20, fragment de cotte de maille; 18, clef; 21, pointe de trait inachevée, en cours de forgeage; 22, petit pain de suif; 28, 30, 33, 34, fibules; 25, boucle de ceinturon; 24, passant de courroies; 23, 27, 31, 35, 38, appliques diverses; 36, couvercle de boîte à parfum; 39, écaille de lorica squamata; 26, 37, éping'es; 40, objel énigmatique en bronze. II. Couche d'incendie de 235: 41 à 45, céramique du III siècle; 51 à 57 (sauf 54), céramique dı $\mathrm{rI}^{\circ}$ siècle; 48, fragment de lampe en bronze; 46, 47, 50 et 54, pieces en fer ou en bronze d'une voiture ou d'une machine de gurerre. 
blai ont atí apportés d'ailleurs, et vraisemblablement des faubourgs situés non loin de là, extra muros, dans la région de l'église Saint-Guillaume et dans le quartier de la Krutenau, à une centaine de mètres du rempart, au-delà de l'Ill. Nous savons en effet, d'après la stratigraphie des habitats romains situés en dehors de l'enceinte (fouilles de l'église Saint-Nicolas) ${ }^{10}$, que les faubourgs ont élé brûlés sous Mare Aurèle, vraisemblablement ì la suite d'une incursion de Mareomans, entre 170 et 175 .

5" l'estiges des casernements du temps des Séveres, incendiés en 235.

Au début du mre siècle, ces demeures arlisanales furent rasíes à leur tour, et l'emplacement récupéré par l'armée pour y ídifier des baraquements en bois et en torchis, du genre de ceux que nous avons découverts sous l'église Saint-Etienne en $1948^{11}$. Ceux de la ruelle Saint-Médard furent ígalement détruits en 235 ap. J.-G., sous Alexandre Sévère. Leurs vestiges se présentaient tout ì fail de la même façon : c'étaient de larges poches creusées dans les couches sous jacentes, et remplies de débris calcinés provenant des murs en forchis et des loits couverts de tuiles à rebords. Quclques marques de la virre légion, quelques armes ou outils en fer, ainsi que les restes malheureusement presque completement corrodés par l'oxydation d'une voilure ou d'une machine de guerre de pelite taille, ont pu être recueillis ì ce niveau (fig. 9, 46, 47, 50, 54).

$6^{\circ}$ V'estiges d'une rue et d'une place du $I I^{\mathrm{e}}$ siècle.

Au-dessus des restes de baraquements brûlés en 235, a été installée, vraisemblablement lors de la reconstruction du camp sous Maximin, une rue en cailloutis, pourvue d'une rigole (fig. 8). Elle longeait un ensemble, dont les seuls vestiges qui nous soient parvenus sont des lémoins de sols, en terrazzo, trís soigneusement aménagés (fig. 10). Nous arouls noté trois sols supelposés, ee qui suppose une assez longue durée d'ulilisalion, depuis la période de restauration du camp, sous Maximin, jusqu'au début du rve siècle. In deuxième eouche de terrazzo contenait une monnaie de Tétricus fils.

Quelle élail la nature de cet ensemble ? I.es nombreux blocs de grès taillé, trouvés dans les couches de remblai et daus les vesliges d'aménagements ultérieurs, la présence d'un fût et d'une base de colonne, d'un balustre, remployés dans les construclions plus tardives (fig. 14), nous incline à le considérer comme une place pourvue d'un petit sancluaire de carrefour. Cette hypothèse est confirmée par la découverte, ì date ancienne, ì eet emplacement, d'un

(10) Caliers dedreheologie et d'llistoire didsace, 1952, p. 70 at suiv.

(11) Ibid., 1949, p. 260 et suiv. 


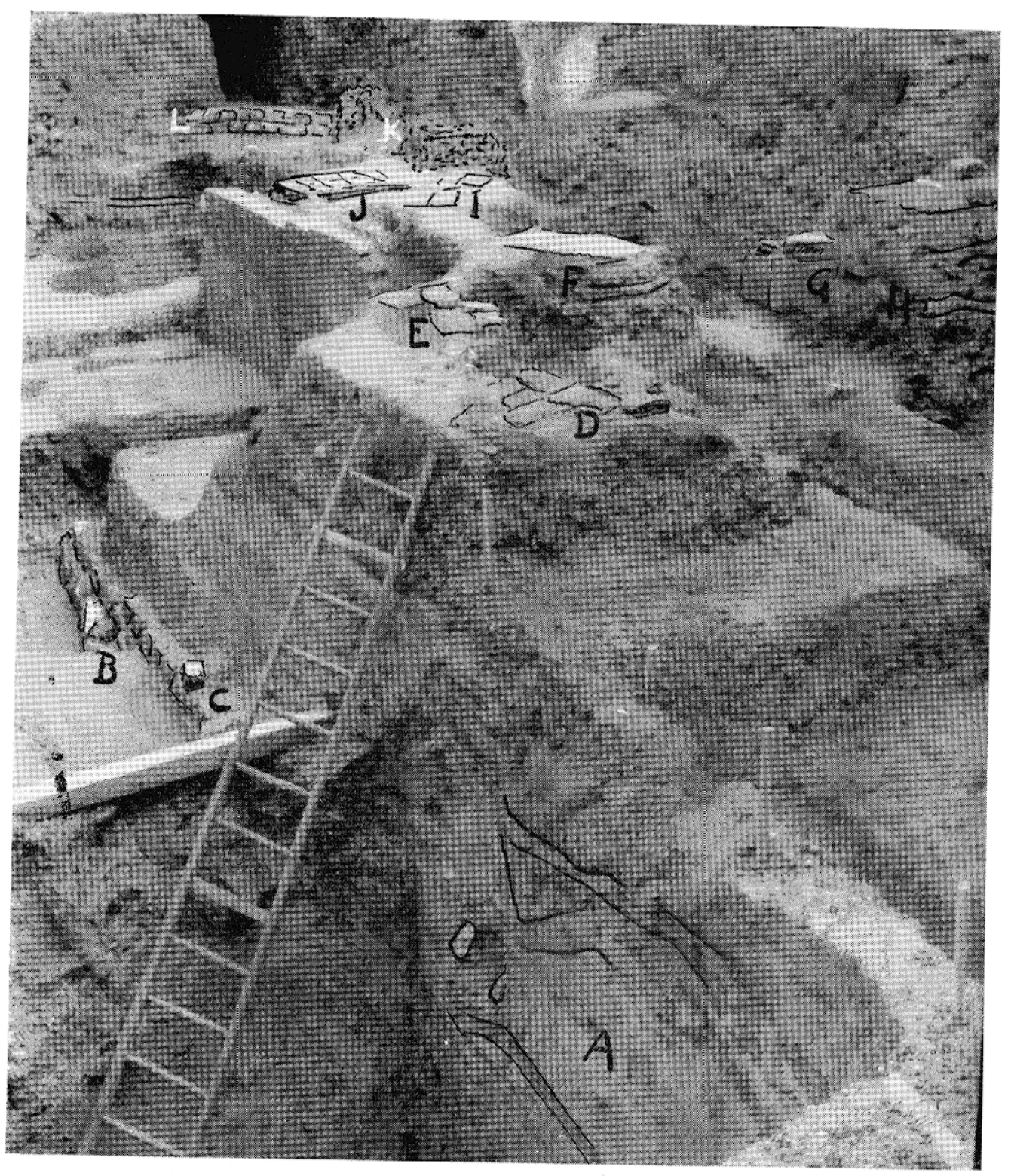

Fic. 10. - Vue générale du chanlier, d'ouest en Est: A, coupe au-dessus du fossé de Tibère; $\mathrm{B}$, hérisson; $\mathrm{C}$, mur d'Hadrien; $\mathrm{D}$, sol de Valentinien; $\mathrm{E}$, sol de Gratien; $\mathrm{F}$, témoins de sols du $\mathrm{II}^{\mathrm{e}}$ siècle; $\mathrm{G}, \mathrm{mur}$ de forlune du temps de Valentinien; H, sol de Valentjnien; I, sol de Théodose; J, mur de Gratien; $\mathrm{K}$, mur en torchis brùle du temps de Théodose; L, mur de Gralien.

acrotère de fronton en grès rouge, décoré d'un buste monumental de déesse mère, dont le style est tardif et barbare. Il y avait donc là, vraisemblablement, un important croisement, une place, et un temple dédié aux déesses mères et ạu diṿinités des carrefours. 
7" Greniers à bles superposés du IV'e siecle.

Ullérienemenent, sous Gonstantin, au débul du ive siècle, l'emplacement a ćlé creusé, en enntrobas de la route, et on y a ménagé une sćrie de caniveaux el de puisards (fig. 11-12). Il est couvert d'un sol en loess mêlé de chaux, soigneusement damé, et paraît avoir servi de sous-sol à un assez vaste hangar, destiné à abriler des provisions de blé. Ce grenier d'abondance était construit essenliellement en bois, les bases des poutres de la charpente reposant sur des blocs de piere provenant de constructions anterieures. Son plancher en bois dominait le sous-sol de $0^{\mathrm{m}}, 60$ environ, on y aceédail de la rue, qui était encore en usage a celte époque. les monnaies découvertes dans le sol damé (Sćvère, Constantin, Licinius) permetlent de dater l'ensemble du début du ive siècle (vers 310). Ce hangar a été anéanli par un incendie. La couche de destruction contenait des fragmenls de pisé calciné, des ferrures oxydées et parfois à moilić fondues par la chaleur, ainsi qu'une grande abondance de grains de blé carbonisés. Des monnaies, de Constant, Constance II, Magnence et Dé. cence permeltent de dater ce sinistre avec précision (355 ap. J.-G.) ${ }^{12}$. - Le hangar a élé ensuite reconstruit, sous Valentinien, et la rue déplacée vers le Nord-Ouest. Une partie du mur du grenier de Valentinien, construit en torehis, mêlé de pierres appareillées, a élé mise au jour au-dessus de la roule du ${ }_{11 I^{\mathrm{e}}}$ siècle, dont elle n'est séparée que par une minee eouche de charbons de bois el de cendres, constiluant l'horizon d'incendie de 355. Ailleurs, des moellons, un fût de colonne el des malíriaux provenant d'édifices antérieurs avaient été placés au-dessus de la couche de grains brûlís de 355 (voir fig. 10, (a), pour constituer un murel de fortune, destiné vraisemblablement ì servir de fondement à la charpente du grenier de Valentinien (voir fig. 11-12). Un sol, partie en loess jaune pâle, et partie en briques, recouvrait la couche d'incendic de 355 .

I.e hangar de Valentinien a été de nouveau délruit par un incendie, daté par des monnaies de Valentinien, de Valens et de Gratien. S'agil-il d'un sinistre localisé, ou bien d'une destruction totale, dûe à l'invasion des Alamans en 377, avant la bataille de Horbourg? Il faut attendre, pour se prononcer définilivement ì ce sujel, d'avoir relrouvé en d'autres endroits la même couche d'incendie.

Sous Giatien, a élé édifié un nouvel ensemble, qui nous est parvenu sous la forme de deux petits mur's maçonnés (voir fig. 10, 13 et 15), et d'un sol, partiellement en tuiles à rebords, et partiellement en mortier blanc ou rose. Ces murs ont été rasés, à la fin du Iv siècle, pour être remplacés par un nouveau

(12) Ibid., 1949, p. 272 et suiv. 

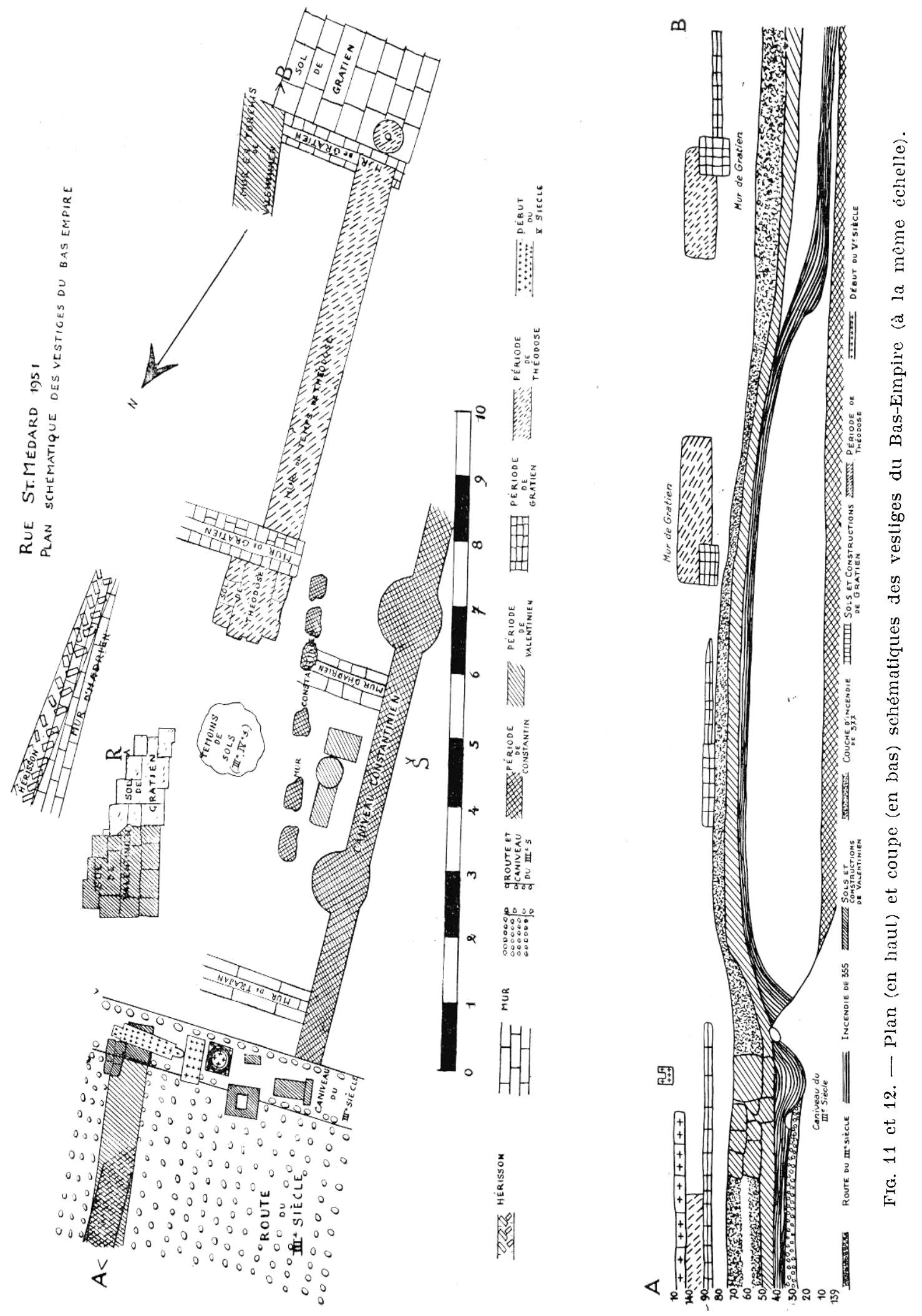


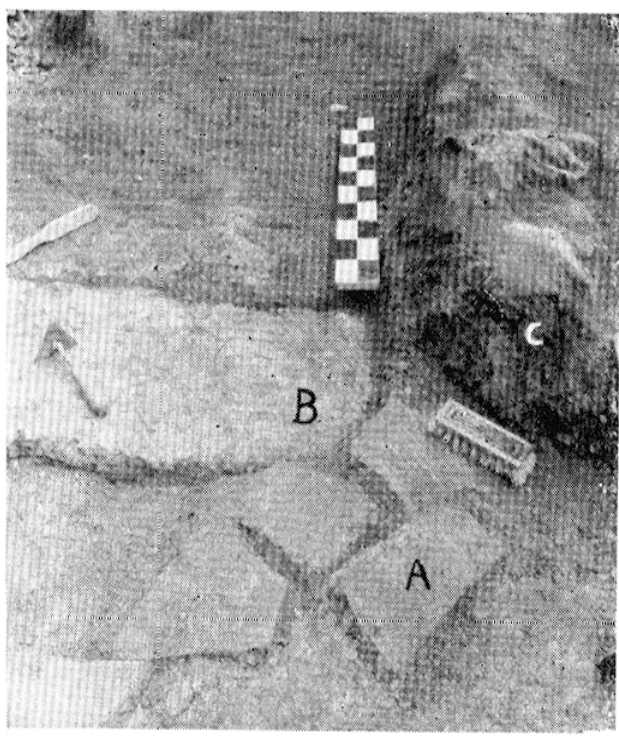

Fra. 13. - Superposition des vestiges du IV siècle: $\Lambda$, sol de 'Théodose; $B$, mur de Gratien; $\mathrm{G}$, mur on torehis brîlé de Théolose.

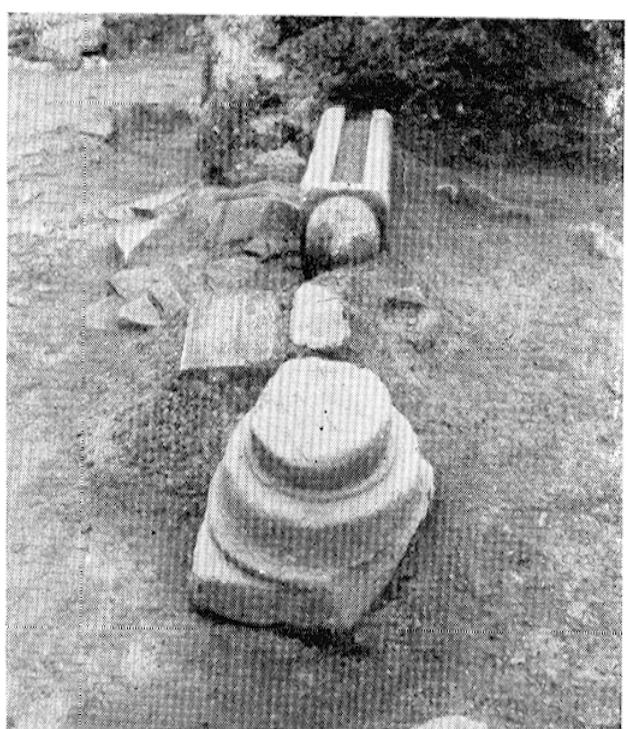

Frg. 14. - Base de colonne et balustre, ayanl servi de fondalions a une baraque du $v^{*}$ siècle.

hangar en bois, aux parois en torchis (voir fig. 10 el 13). Ces murs en pisí, et le sol de ce dernier édifice ont été calcinés par un dernier incendie. Ce niveau est daté par des monnaies de Maxime et d'Honorius. Nous ne pouvons pas non plus décider encore de façon certaine s'il s'agit là d'un sinistre partiel, ou d'une destruction totale de la ville, au moment où les Alamans se sont emparés définilivement de l'Alsace au ve siècle.

$8^{\circ}$ Rue dallée, hases d'une baraque des derniers temps romains.

Einfin, encope au début du ve siècle, el postérienrement à ee denier incendie, a éló amínagíe, au-dessus de l'ancienne rue du mire siècle, une rue dont le sol élait consliluć par des fragments de tuiles à rebords, souvent marquíes du chrisme constantinien, ou de l'estampille de la XIIe légion Victrix.

Des matériaux remployés: base de colonne en grès rouge, fragment de balustrade en pierre calcaire (roir fig. 14) ont été placés régulièrement et intentionnellement le long de ce sol. Ils proviennent vaisemblablement d'habitations très sommairement ronstruites, en bois on er torchis, dont le poutrage s'appuyait sur ces pierres, en guise de iondations. Il s'agit là d'installations appartenant à l'extrême fin de la période romaine, après la conquête des hlamans, sans doute. Il ne semble pas qu'elles aien. duré trìs longtemps. Quant à la période mérovingienue, olle est marquée, iei comme 
presque partour aillent's en ville, par une inter'uption totale dans le séjour des hommes. Le terrain était derenu désẹt, et oceupé par des broussailles ou un petit bois, peuplé d'esiargots.

La même couche de terre grise, riche en coquilles de mollusiunes terrestres, a été observée ici, et à l'église de Saint-Elienne, au-dessus des derniers vestiges romains ${ }^{13}$. Or, nous savons par des documents que l'emplacement de l'abbaye de Saint- Ltienne était, jusqu'en 722, complètement désert. Ce n'est qu'à l'époque carolingienne que de nouvelles demeures se sont établies à cet endroit. Nous avons trouvé, dans les couches romaines, des fonds de couches : caves, puisards, contenant, de nombreux tessons datant de cette époque. L'occupation s'est poursuivie pendant tout le Moyen âge. Des puits vastes et profonds contenaient de la céramique et des objets du Xiv siècle.

Conclusions provisoires sur les deux campagnes de fouilles dans le quartier de la ruelle et de l'impasse Saint-Médard (1951-1952).

L'histoire du quarlier de la ruelle et de l'impasse Saint-Médard apparaît donc, ì la lumière des dernières fouilles, comme singulièrement compliquée.

Occupé d'abord par un fossé et un rempart en bois ćlevé par la ITe légion au début du règne de Tibère, l'emplacement devait ensuite être désaffecté sous Claude, et abandomé à la population civile. Des habilations indigènes s'y élevèrent alors, qui furent détruites par l'incendie de 70 .

Ce fut ensuite la via sagularis flavienne, et l'emplacement d'un carrefour de voies intérieures, constituant l'angle d'une striga.

Sous T'rajan, et par suite de l'extension du camp, dont l'enceinte se l'ouve reportée à une dizaine de mètres plus à l'Est, le carrefour est également déplacé. Lne première séric do bâtiments, décorés de fresques, devait s'élever à sa place. A ces premiers édifices en succédaient d'aulres sous Hadrien, vers 120 ap. J.-C. Il est évidemment difficile d'en préciser avee certitude la deslination. Nous croyons loutefois que l'on peut les altribucr avec quelque vraisemblance a des locaux de réunion pour les sous-officiers, du genre de ceux qui ont été trouvés à V'etera et à Novaesium. Ce n'étaient assurément pas des chambrées ordinaires de simples soldals, et pas non plus les demeures des officiers, ces dernières étant situćes dans le voisinage de la rue du Sanglier.

Puis, après l'abandon quasi tolal du camp de la VIIIe légion, dont les effectifs devaient être, à partir de 160 ap. J.-G., enlièremenl réparlis dans les camps du limes, ce territoire fut de nouveau livré à la population civile. Des artisans indigènes s'y installèrent jusqu'au début du $\mathrm{III}^{\mathrm{e}}$ siècle.

A cette époque, le terrain fut récupéré par l'autorité militaire, pour être couvert de baraquements en bois. Ces derniers furent détruits par l'incendie de 235:

(13) Ibid., p. 257. 


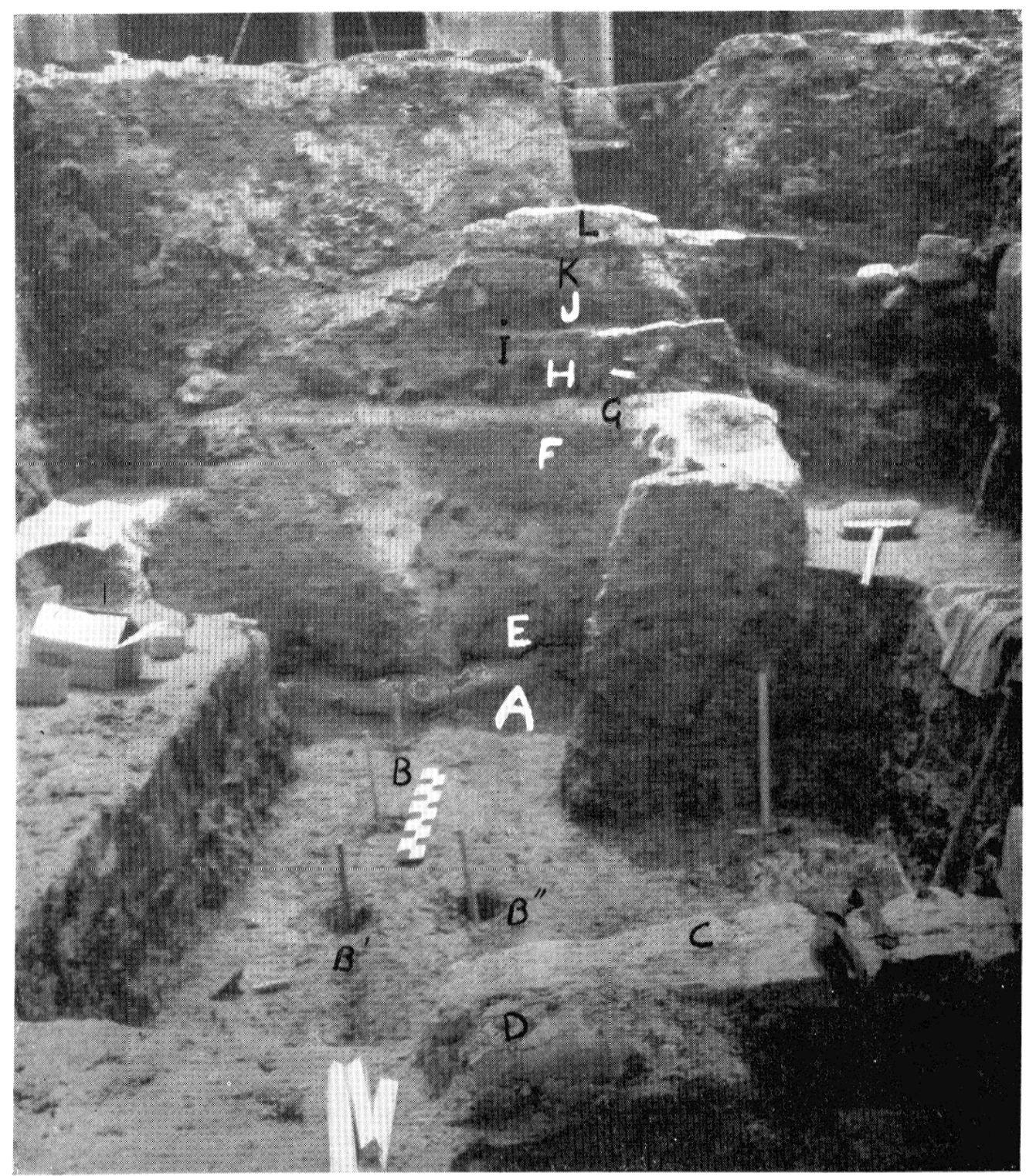

FIG. 15. - La stratigraphie dans les parties orientales du chanlier (pholographie prise en contrejour, avec un filtre rouge): $\Lambda$, incendie de $70 ; B, B^{*}, B^{\prime \prime}$, trous de polcaux (Claude-Néron); (a, mur du temps d'Hadrien; D, plinthe en terrazo du mul d'Iadrien; $\mathrm{E}$, incendie de 97; $\mathrm{l}$, incendie de $235 ; \mathrm{G}$, sol constantinien; II, incendie de 355 ; I, sol de Valentinien; J, incendic de 377 ; K, sol de Gralien; L, Mur de Gratien.

Alor's se place l'épisode encore mystérieux dont nous avons découvert quelques traces en 1951 : l'aménagement d'une place, pourvue d'un sol en terrazzo. L'emplacement a toujours été un carrefour à l'époque romaine. Un buste monumental de déesse mère, naguère étudié par M. A. Grenier (conférence 


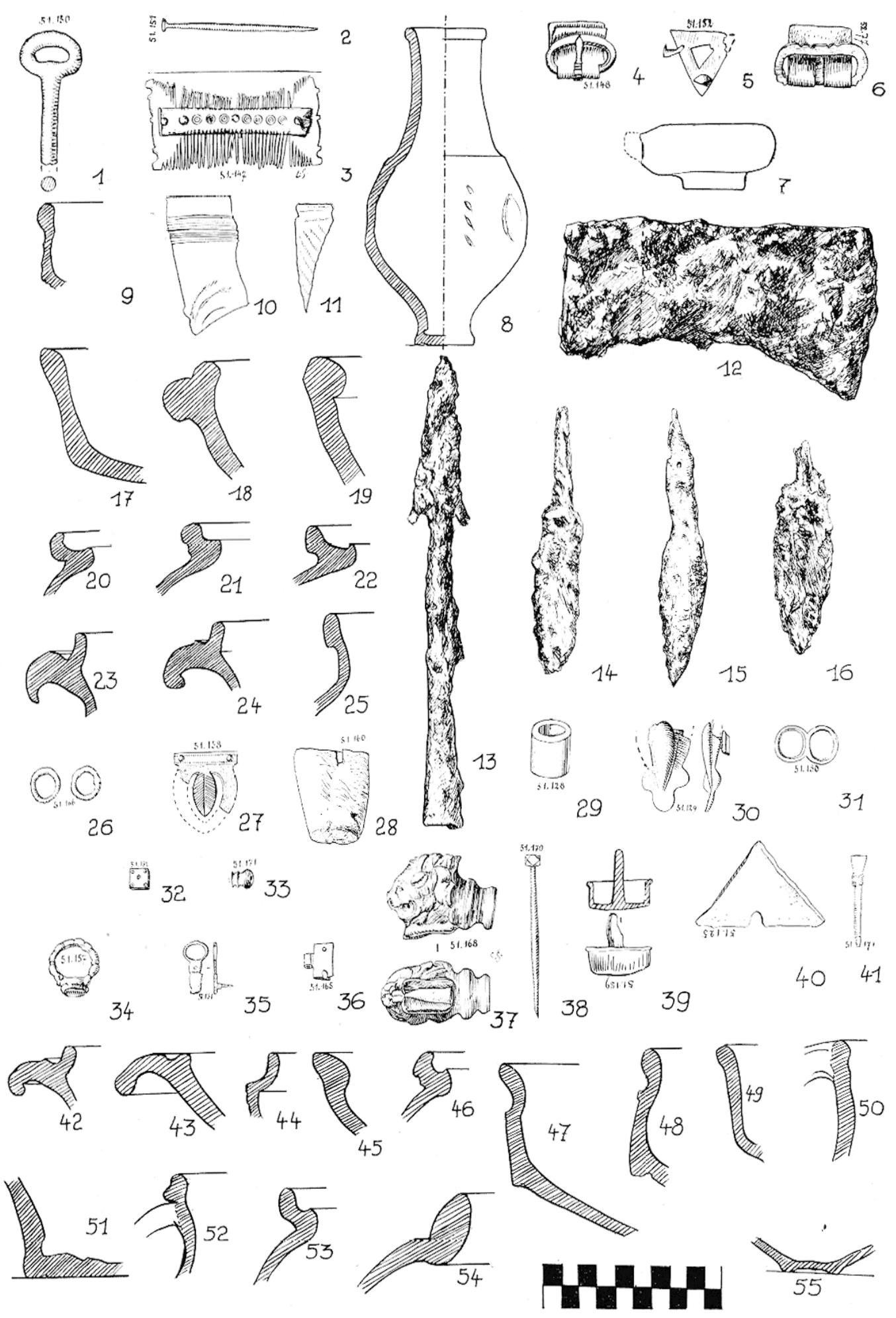

FiG. 16. - Céramique et objels découverts dans les couches du rve siécle : I. Incondie de $37 \%$ : 1 , objet en fer; 2 , spingle en os; 3 , pcigne en os; 4, 6, boucles de ceinlure; 7 , lampe en céramique de l'Eifel; $\dot{8}$, gobelet en terra nigra de basse époque; 9 , 17, terra nigra; 10, 11, verres romains tardifs; 12 a 16 , hache, angon, couteaux de type germanique; 18 , rebord de mortier; 19, rebord d'assiette de forme indigène, en céramiquc très grossièreç 20, 21, 22, 25, rebords de vases ovoïdes et de pichet en céramique de l'Eifel; 23,24 , rebords de morticrs. II. Incendie de 355 et couches diverses du IV siècle: 26, anneaux de bronze; 27, boucle de ceinture; 28 , petit pot en bronze ;32, dé à jouer, en os; 33 , partie de grande libule en bronze doré; 34 , bague en bronze, à chaton en fer (anneau sigillaire?); 35 , 36 , objets de bronze; 29, virole de couteau en os; 30, attache d'onochoé en bronze; 31, passant de courroie en bronze; 37 , petit lion en bronze (déversoir de fonlaine); 38, épingle en os; 39, objet en lronze; 40, altache d'anse de chaudron, en hronze; 41, morceau d'une pince à ćpiler'; 42 a

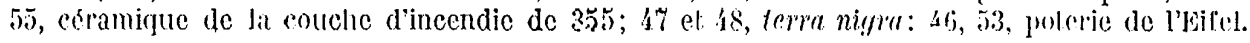


Inédite, v. Mém. Soc. Con.s. Mon. Hist. Als., XXV1, p. 179), provient d'une des maisons de la ruelle Saint-Médard, dans le mur de laquelle il était encasIré. Nous avons trouvé, d'autre part, réemployés dans les murs de fortune du IV ${ }^{\text {e }}$ siècle, une base et un fût de colonne, ainsi qu'un balustre de pierre. La place, installée au $\mathrm{III}^{\ominus}$ siècle, après l'incendie de 235, n'aurait-elle pas été occupće par un petit sanctuaire, dédié aux déesses des carrefours?

Sous le règne de Constantin, elle devait être détruite, surcreusée pour servir de cave et de rez de chaussée a un grenier à grains, construit en bois. Ce dernier devait être incendić une première fois en 355, sous Cianstance Il, reconstruit sous Julien ou Valentinien, puis anéanti à nouveau en 377 ap. J.-C., sous (aratien. Dans la suite, de petils bâtiments en pierres maçonnées, pourvus de sols en briques, devaient être aménagís loul près de l'enceinte. Il s'agit sans doule de baraquements et d'abris a l'usage de la garde des remparts, dans le genre de ceux qui ont élé trouvés à Alzey par G. Bersu.

Ils devaient être remplacés, à l'extrême fin du IV siècle, par un nouvel chage de mur's en torehis, appartenant à de nouveaux grenier's à grains du temps de Théodose. In dernier incendie les détruisit, qui fut suivi d'me ultime reslauration.

Cie ne sont cerles pas les moins émouvants des vestiges gallo-pomains dícouverts à Strasbourg que ee dallage en tuiles, marquées du chrisme, ces fondations sommaires en matériaux de remploi, qui nous montrent, au cours de la première moilió du ve siècle, la vie gallo-romaine se maintenir dans cette cilé d'argentorale, tant de fois submergie par le flot des envahisseurs, loujours menacéce, mais si obstinćment reconstruite.

\section{APPENDICE I}

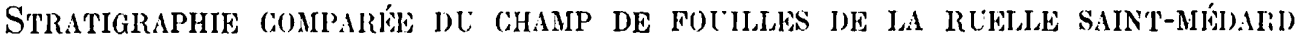
FT DE CELUt DE L'ÉGLISE SAINT-ETIENNE

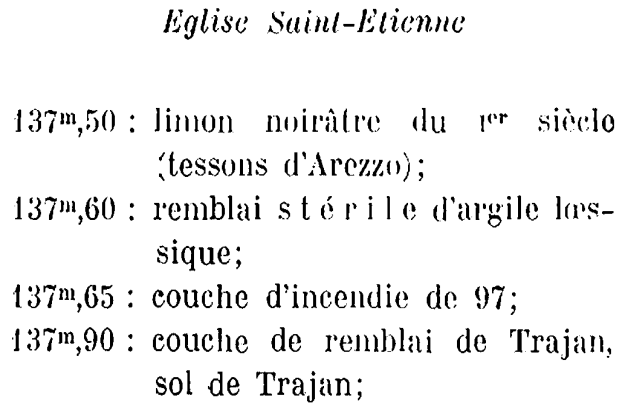

Eglise Suint-Eticnne

$\left.137^{m}, 50\right)$ : limon noirate du $\mathrm{f}^{\mathrm{rr}}$ sièclo :tessons d'itrezzo);

$137^{m}, 60$ : remblai stérile d'argile lorssique;

137'm,65: couche d'incendie de 97;

$137^{m}, 90$ : couche de remblai de Trajan, sol de Trajan;

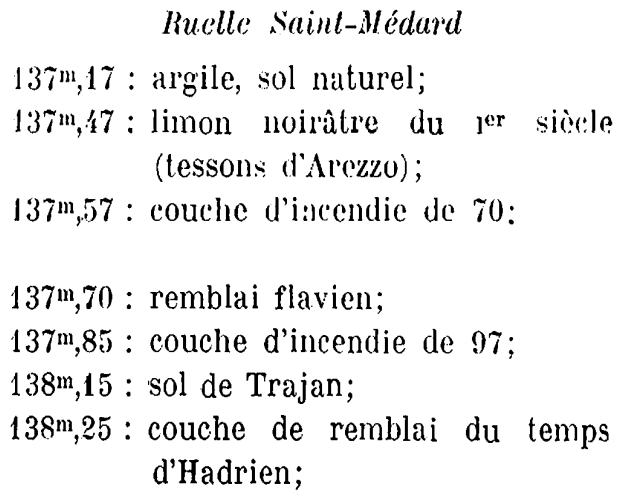

Ruelle saint-Médard

$137^{m}, 17$ : argile, sol naturel;

$137^{m}, 47$ : limon noirâtre du jer $^{\text {siocle }}$ (tessons d'Arezzo);

137m,57: couche d'iacendie de 70 :

$137^{m}, 70$ : remblai flavien;

137m,85: couche d'incendie de 97 ;

138m,15 : sol de Trajan;

138m,25: couche de remblai du temps d'Hadrien; 


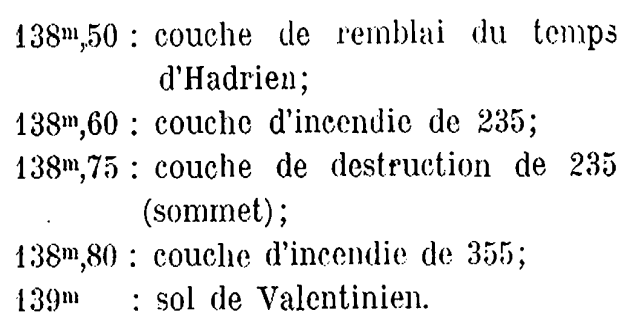

138 ${ }^{\mathrm{m}}, 35$ : sol du temps d'Hadrien;

$138^{\mathrm{m}}, 50$ : sol des habitations indigènes du temps d'Antonin;

138'm,61 : sol du début du III siècle;

$138^{m}, 81$ : incendic de 235

138m,91: sol de Constantin;

139m,30: incendie de 355 ;

$139 \mathrm{~m}, 40$ : sol de Valentinien;

139m, $\% 0$ : incendie de Gratien (377?); - 139m,51 : jer lerrazzo de la place du IIre siòcle; $-139 \mathrm{~m}, 74$ :

$3^{\text {e }}$ terrazıo de la place du $\mathrm{II}^{\mathrm{e}}$ siècle;

$139^{m}, 80: r^{\circ}$ cmblai de Gratien;

139m,85: sol de Gratien;

$140^{\mathrm{m}}$ : couche d'incendie du débul du $v^{e}$ siècle;

$140 \mathrm{~m}, 20:$ ruc dallée en tuiles de la rremière moitić da ve siècle

\section{APPENDICE II}

\section{INVFNTAIRE SOMMAIRE DES MONNAIFS}

A) Conche d'habitats de la fin du II" siecle :

Un denier fourré de Marc Aurèle, revers fruste.

B) Remblai du díbut du $\mathrm{III}^{\mathrm{e}}$ siècl.', sol du. lemps des Sévères:

Un MB de Tibèrc à l'autel de Lyon.

Cin quinaire défourré de septime sévère, Cohen 793, 202 ap. J.-G.

Un denier de Julia Domna, Gohen 58.

C) Couche d'incendie de 235 :

Un GB d'Hadrien, revers fruste.

D) Rigole de la rue du III siècle :

Imitation barbare d'une monnaic de Tétricus père.

F) Deuxième sol en terrazzo de la place du III siècle :

$\mathrm{PB}$ de Tétricus fils, Cohen 87 ou 88.
F) Sol du temps de Constantin: PB de Tétricus, Iz SPES $\Lambda$ UGG.

P'B de Licinius, Cohen 49.

MB de Constance Chlore, Cohen 71 .

MB de Sévère II. Cohen $2 \%$.

PB de Constantin, Cohen 519.

G) Couche dincendie do 355:

a) Mounaies du III $^{\mathrm{e}}$ siècle :

PB de Salonin Cohen 8.

PB de Gallien, Cohen 165.

2 imitations barbares des monnaies de Tétricuss père.

$P B$ de Tétricus père, Cohen 158.

PB de Claude II, Cohen 115.

Imitation barbare d'une monnaic de Claude II, R CONCORIDIA FXXRCITuU.r.

b) Monnaies du IV siècle:

$2 \mathrm{~PB}$ de Constantinople, Cohen 12 et 21. 
2 P'B Lros Roma, Cohen 18.

7 PB de Constantin, Cohen 123, 214, 246,

251, 254, 530, 570 .

3 PB de Théodora 2 Cohen 1 , ct 3 .

2 PB de Constant, Cohen 5/4 et 176.

2 PB de Constance II, Cohen 31 et 92.

2 NB de Magnenee, Cohen 5 el 16.

1 VIB de Déennee, Cohen 20.

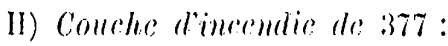

a) Honnaies du mir siocle:

PB de Gallien, Golsen 979 .

Imitation barbare d'une monnaie de Té-

tricus père.

PB de Quintille, revers fruste.

P'B de Claude, revers fruste.

b) Mommaies du re siocle:

2 P'B de Constantin II, Colien 11:3 ot 11'.

1 MB de Crispus, Cohen 19.

2 PIS lives Roma, Cohen 15.
2 MB de Magnence, Cohon 16.

PB de Constant ou Constance II, lz GI.ORIA EXERCITUS.

2 MB de Constant, Colien 9 et 18.

3 PB de Constant, Colien 15, 73, 176.

5 P'B de Constance II, Cohen 94, 10.', 182, 283, 334 .

5) PB de Valentinien I, Colen 11, 12, 37, 47, et revers fruste.

5 PI3 de Valens, 2 Cohen 11, 3 Cohen 17. 5 Pls de Gablien, Cohen J2, 2 Cohen 18, 22,24 .

1) Couche dincendic du début du v siècle :

PB do Gallien, revers indistinct.

PB de claude II, Cohen 11.

2 PB de Constant, Cohen 51 et 5.4.

PB de Théodose, Colıen 30.

MB de Maxime, Cohen 3.

PI3 d'Ilonorius, Cohen 2.).

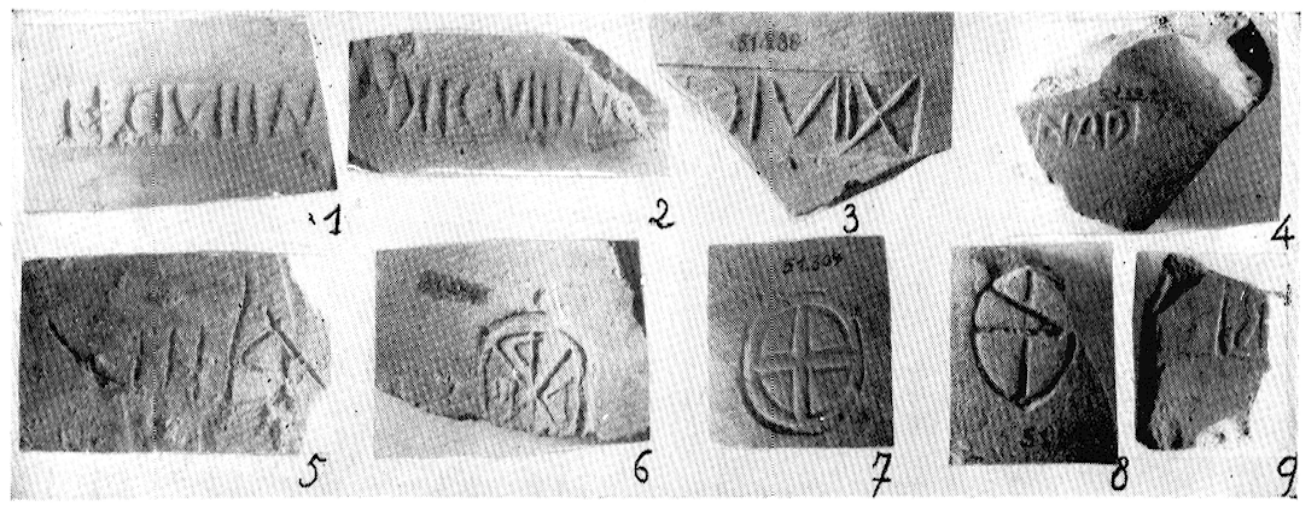

Fis. 17. -- Marques sur tuiles: 1, 2, marques de la VIII légion Augusle, Irouvées dans le mur de Trajan; 3, 4, 5, 9, marques militaires trouvées dans les couches d'incendie de 355;

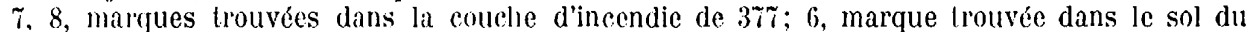
débul. du $v^{\mathrm{c}}$ siécle. - La marque $n^{\circ} 3$ provient de la XII légion Victrix; la marque $n^{n} 4$, d'un eorps de Ménapes; la marcque n* 9 . de la Ire légion Marlja (marque rélrngrade). 